\title{
Effect of transient drying on mechanical properties of concrete specimens
}

\author{
François Soleilhet ${ }^{1,2}$, Farid Benboudjema ${ }^{2}$, Xavier Jourdain², Fabrice Gatuingt ${ }^{2, *}$ \\ ${ }^{1}$ EDF R\&D, Les Renardières, 77250 Écuelles, France \\ ${ }^{2}$ LMT ENS-Paris-Saclay, CNRS Université Paris-Saclay, 91190 Gif-sur-Yvette, France \\ * corresponding author: fabrice.gatuingt@ens-paris-saclay.fr
}

\begin{abstract}
Initially saturated, cementitious materials are subject to water movements that are responsible for multiple phenomena. Among them, there are drying shrinkage, creep, fluid transport, swelling reactions and cracking induced changes in mechanical properties. The main objective of this study is therefore to investigate the impact of drying on the behaviour of cementitious materials. For this we carried out two 70-day studies on the material EDF's VeRCoRs project. The studies consist of storing (after almost complete hydration) a batch of specimen under saturated conditions while the second batch is stored in controlled environments of $30 \%$ and $45 \% h_{r}$ respectively. After the drying phase, specimens are tested by the mean of standard mechanical tests. The conclusions are heterogeneous. For instance, on different specimens that are not in water balance, the compressive strength is increased by a maximum of $12 \%$ while the tensile strength determined by bending is more dependent on the type of tests. The elastic modulus decreases with desaturation. Finally, the energy dissipated by the cracking increases sharply with drying. These results show that the hygro-mechanical behaviour is complex, depending on the ambiant conditions and its duration, the geometry of the specimens and the type of tests. Thus, to take into account the hydric effects on mechanical behaviour, it is necessary to have a numerical modelling approach to take into account the different mechanisms involved. In this perspective, this work provides a significant database that offers the opportunity to test hygro-mechanical models. A necessary step in order to model structures.

Keywords : Drying; Drying Shrinkage; Internal Stresses; Mechanical properties; Hygro-Mechanical models
\end{abstract}

\section{Introduction}

The performance of Portland cement-based materials under drying is very difficult to assess. The impact of drying on performances is more complex than for any other materials. Not only because concrete is a composite material, with different properties for each component, but also because its properties depend on parameters such as mix proportion (which affects porosity, strength) [1] or geometry among others. Moisture effects are multiple and occur at different scales. First of all, there is a competition between drying and hydration. As a result, moist curing plays an important role on strength development and durability of concrete [2]. Second of all, drying shrinkage appears as a macroscopic consequence of drying. As drying is a slow process due to the low concrete's permeability, steep hygral-gradients develop and lead to differential drying shrinkage between the edge and the core of the structure. Thus, tensile stresses appear on the surface which are selfequilibrated by compression of the core. If these stresses reach the tensile strength, cracking may occur (as illustrated on figure 1). On this scale, there are also strains incompatibilities between 
components, like for instance reinforcements and cement pastes, aggregates and cement pastes [3, 4], anhydrous cement paste and C-S-H or incompatibilities due to the geometry. Finally, at nano-scales, drying modifies the physical characteristics of Calcium Silicate Hydrate (C-S-H) [5]. Lastly, effects due to hygral gradients also bring mechanisms such as capillary pressure, disjoining pressure and surface energy which are closely linked to drying shrinkage (see for instance [6]) but which bring also positive effects. Indeed, the increase in isotropic capillary pressure [7,8], acts like an isotropic pre-stressing and positively increases the material rigidity.

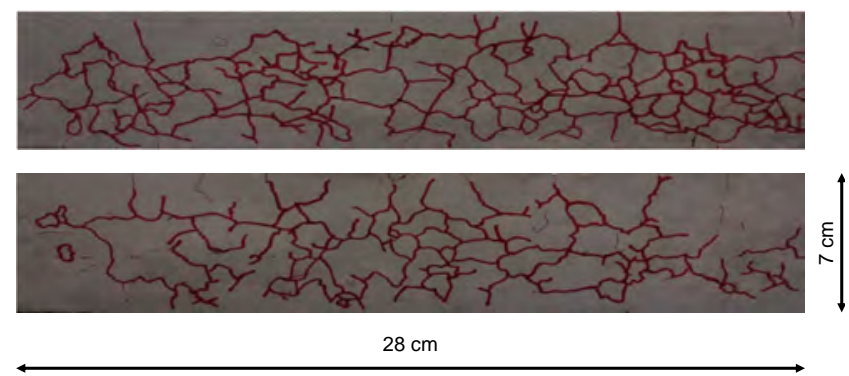

Figure 1: Illustration of concrete skin cracking induced by drying on $7 \times 7 \times 28 \mathrm{~cm}^{3}$ parallepipedic sample

Cracking induced by drying has an impact on the serviceability. For structures like tanks, nuclear containment vessels, dams or tunnels, this cracking may significantly increase concrete permeability and reduce tightness [9, 10]. For other structures (bridges, buildings), the serviceability may be reduced due to the penetration of aggressive species (such as carbon dioxide, sulphate and chloride ions). Regarding mechanical properties, a review of the literature shows that the impacts are various and sometimes significant; increases of compressive strength with drying [11, 12, 13, 14] or we can also find decreases $[14,15,16]$. It is the same for tensile strength in splitting test [11, 17] and in bending tensile test [18]. Nevertheless, most authors report a decrease of elastic modulus [19, 13, 20]. These effects at the material scale can also be seen at the structural scale [21].

Even if drying tests on plane concrete specimens are not representative for the behavior of large reinforced or prestressed concrete structures, we focused our studies on them. Indeed, in order to model reinforced or prestress concrete structures submitted to drying, it is crucial to understand and model the behaviour of concrete at the material scale. Concrete may crack due to drying shrinkage gradients. Reinforcement may limit crack opening, but it also restrains drying shrinkage. The correct prediction of the force at first cracking needs to take into account drying shrinkage of concrete (if the structure is drying), see [22]. Drying shrinkage cracking modifies also the bond between concrete and the steel rebar. In the case of prestressed structures such as containment buildings of nuclear power plants, prestress is applied after several months of casting and concrete may have crack. Finally, drying leads to a redistribution of the compressive stresses applied by the prestress.

The hygro-mechanical behaviour of a cementitious material is a complex problem [23, 24]. The hydric status (evolution of mass variation, desorption isotherm, hydric fields) is a difficult state to determine. It is then necessary to know the evolution of the drying shrinkage as well as the creep that will relax the internal stresses. Cracking can appear and make the problem complex. Finally, we can place ourselves in a case where hydration evolves and competes with drying. All these factors together lead to a large number of unknown factors with few calibration means. It is necessary to have a material characterized from a hydric and mechanical point of view to be able to conduct predictive modeling at the scale of the structure.

The main interest of the present study is the behaviour of concrete materials, subjected to drying. Most existing studies focus on the mechanical response with a water balance. The aim of our work is then to focus on a complementary case in a transitional phase, representative of the service conditions of real structures. The secondary objective of the study is about the various states and conditions 
regarding drying of the material: porosity, isotherm, delayed strains (drying shrinkage and creep) and finally residual mechanical behaviour. This level of insight allows the study to provide informations on the mechanical behaviour of ordinary concrete subjected to drying loading, as well as serve as an experimental basis for calibrating hygro-mechanical models.

\section{Experimental program}

The main goal of this experiment is to investigate the impact of drying on the mechanical properties of ordinary concrete in service life. To do this, the effect of two environmental conditions (severe and very severe) respectively $30 \%$ and $45 \% h_{r}$ are investigated through standard mechanical tests. Specimens made with the same materials are kept in $100 \%$ saturated conditions to be used as reference specimens. Drying is a slow process, about $10^{3}$ to $10^{6}$ times slower than thermal diffusion. The process of moisture equilibrium with the ambient environment is therefore very long. For massive structures, the balance may not be achieved during the service life. In order to be representative of the conditions of massive structures (not at moisture equilibrium), the samples were tested after 70 days of drying.

\subsection{Materials}

To maximise the effect of drying shrinkage, the material used in this study is an ordinary concrete with a high water to cement ratio $(\mathrm{w} / \mathrm{c}=0.62)$. This material is the one considered in the VeRCoRs project led by EDF [25]. The mix proportions of each component are given in the table 1 . The concrete is made with an Ordinary Portland Cement, limestone aggregates and a plasticizer is added. Its usual mechanical characteristics are: an average compressive strength at 28 days of $40.6 \mathrm{MPa}$ and a tensile strength obtained by splitting test of $3.5 \mathrm{MPa}$ both on $16 \times 32 \mathrm{~cm}^{2}$ cylinders with an air content of $2 \%$.

\begin{tabular}{lccc}
\hline Coumpound & Nature & Quantity & Unit \\
\hline Cement & CEM I 52,5 R & 320 & $\mathrm{~kg} \mathrm{~m}^{-3}$ \\
Sand & Siliceous & 830 & $\mathrm{~kg} \mathrm{~m}^{-3}$ \\
Aggregate (4-11mm) & Limestone & 445 & $\mathrm{~kg} \mathrm{~m}^{-3}$ \\
Aggregate (8-16mm) & Limestone & 550 & $\mathrm{~kg} \mathrm{~m}^{-3}$ \\
Water (total) & & 197.6 & $\mathrm{~kg} \mathrm{~m}^{-3}$ \\
Plasticizer & SIKAPLAST Techno 80 & 2.75 & $\mathrm{~kg} \mathrm{~m}^{-3}$ \\
\hline
\end{tabular}

Table 1: Concrete mix parameters

To reduce the errors due to the inherent variability in the manufacturing process, all the test specimens for each campaign were manufactured in a single batch and they all followed the same protocol. A first endogenous cure was imposed up to the $7^{\text {th }}$ day after casting. Then the samples were protected from drying by storage in water at an alkaline $\mathrm{pH}$ (close to 12.7 ) up to the $28^{\text {th }}$ day after pouring at an average temperature of $20 \pm 1^{\circ} \mathrm{C}$. At the end of this period, the specimens were separated into two batches. A batch is kept in water as a reference while the rest is placed under relative humidity and temperature controlled conditions.

\subsection{Tests set up}

\subsubsection{Drying and drying shrinkage measurement}

When the specimens are placed under controlled water conditions, they are assumed to be fully saturated. The mass of the samples is regularly measured using two weighting devices with maximal 
capacities and resolution of respectively $16.2 \mathrm{~kg} \pm 0.1 \mathrm{~g}$ and $35 \mathrm{~kg} \pm 10 \mathrm{~g}$. The relative mass variation is then deducted from these successive weighs as:

$$
\left(\frac{\Delta m}{m}\right)(t)=\frac{m(t)-m_{0}}{m_{0}} \leq 0
$$

with $m_{0}$ the initial mass and $m(t)$ the mass at time $t$. In parallel, the ambient relative humidity and temperature are monitored by the mean of a hygrometer. For the storage conditions, the chosen hydric and temperature conditions are in the first campaign $30 \% h_{r}-25{ }^{\circ} \mathrm{C}$ and $45 \% h_{r}-21{ }^{\circ} \mathrm{C}$ for the second one. In the second case, the samples were kept in a room where temperature was monitored but not controlled. However the change in temperature measured during the campaign was between $25^{\circ} \mathrm{C}$ and $21^{\circ} \mathrm{C}$ and did not have a significant influence on the results.

The drying shrinkage tests were classically carried out on $7 \times 7 \times 28 \mathrm{~cm}^{3}$ parallepipedic specimens fitted with shrinkage pins at their ends. The strains were measured in the axial direction using a digital comparator with an accuracy of $1 \mu \mathrm{m}$. After a calibration of the measuring device, the drying shrinkage measurements are made on the three specimens. The integration length used to obtain the associated strains is obtained by averaging the length of each side face of the specimens (see figure 2). Drying shrinkage samples are stored in the second campaign's conditions.

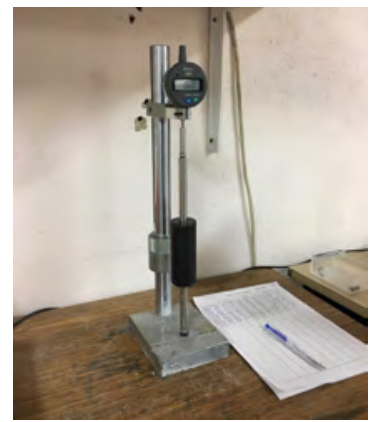

(a)

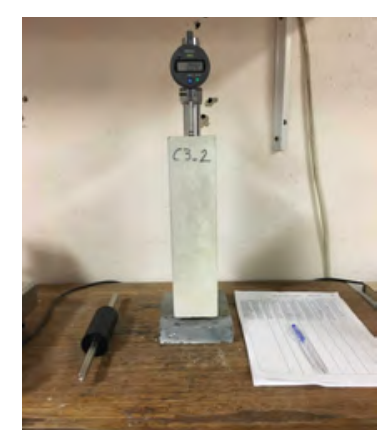

(b)

Figure 2: Device for measuring drying shrinkage : (a) Device calibration and (b) on going shrinkage measurement

\subsubsection{Porosity and drying isotherm}

As part of the study, a characterisation of the porosity accessible to water and of the material isotherm were carried out. The porosity was characterised by following the protocol proposed by the French standard [26]. The samples were obtained in $7 \times 7 \times 28 \mathrm{~cm}^{3}$ specimens made from the same batches as for the "mechanical" specimens. These specimens were cut into samples of $7 \times 7 \times 9$ $\mathrm{cm}^{3}$ size. They were placed in a desiccator for 4 hours to degas before the water was introduced. The period of imbibition of the specimens took 44 hours, then the samples were removed from the desiccators. They were then weighed to obtain the hydrostatic mass $m_{\text {hyd }}$ and the saturated mass $m_{\text {sat }}$ (the balance used has a maximum capacity of $4100 \mathrm{~g}$ and an accuracy of $0.01 \mathrm{~g}$ ). They were finally placed in an oven at a temperature of $60^{\circ} \mathrm{C}$. The drying time depends on the mass variation of the sample over 24 hours. The latter must not exceed $0.05 \%$ within this period. The dry mass $m_{d r y}$ was weighed at the end of the process. This makes it possible to obtain the porosity $\phi$ through the relationship (2).

$$
\phi=\frac{m_{s a t}-m_{d r y}}{m_{s a t}-m_{h y d}}
$$


The gravimetric water content is also reachable by the relation (3).

$$
w_{s a t}=\frac{m_{s a t}-m_{d r y}}{m_{d r y}} \times 100
$$

Among the information needed to characterise the hydric state of a material, the amount of water in the porosity of concrete is of major importance. This information can be hard to assess because static methods like salt solution methods are time consuming. In this study a Dynamic Sorption Balance (DVS) is used as an alternative approach. In the case of cementitious materials and more precisely for concrete this technique may be none representative because of the difficulty to keep the volume fraction of each components. Nevertheless Poyet et al. [27] has developed recently a procedure to correct this aspect to allow the use of DVS for concrete.

The sample tested came from material stored in basic water over one year. They were sawn into $7 \times 7 \times 28 \mathrm{~cm}^{3}$ samples. Then they were hand-crushed resulting in a powder. This powder was sifted to remove grains with diameter above $200 \mu \mathrm{m}$. Finally a mass of approximately $20 \mathrm{mg}$ was extracted and then resaturated for the test. The desorption tests were performed under a temperature of $25^{\circ} \mathrm{C}$ and at a gradually decreasing $h_{r}$ starting at $98 \%$. More informations on the method are available in [27]. Lastly, in order to process the raw data and get rid of variability due to heterogeneity of the material, a point of the desorption isotherm $\left(w_{s m}\left(h_{r}=30 \%\right)\right)$ was calculated by a standard static method in climatic chamber with the same environmental conditions than those presented in section 2.2.1. Thus, in the case of the first campaign for instance, the raw data processing is performed accordingly to equation (4).

$$
w\left(h_{r}\right)=w_{d v s}\left(h_{r}\right) \times \frac{w_{s m}\left(h_{r}=30 \%\right)}{w_{d v s}\left(h_{r}=30 \%\right)} \quad \forall h_{r} \in[0 \% ; 100 \%]
$$

with $w_{s m}$ and $w_{d v s}$ the water content obtained respectively by static method and dynamic vapor sorption.

\subsubsection{Destructive mechanical measurement}

The following paragraph describes the various destructive mechanical tests carried out in this study. Four types of tests were conducted: compression tests, splitting tests, 3-points bending tests on notched and unnotched beams. The compression tests were performed on cylindrical specimens $11 \times 22 \mathrm{~cm}^{2}$. After a surfacing of the sides in contact with the loading plates in order to ensure a good parallelism and planarity, the specimens were tested with a servo-controlled compression tester with a $2500 \mathrm{kN}$ load capacity. The test is force controlled with a loading rate of $5 \mathrm{kN} \mathrm{s}^{-1}(c f$. European standard [28]). The splitting tests were performed on the same testing machine according to the European standard [29]. The imposed force loading rate is $1 \mathrm{kN} \mathrm{s}^{-1}$.

The bending tests were performed on $10 \times 10 \times 84 \mathrm{~cm}^{3}$ specimens. For notched specimens (figure $3 \mathrm{~b}$ ) the notch represents $20 \%$ of beam's height and was made by means of a diamond blade two days before the test. To avoid settlement of supports, the line joining points $\mathrm{A}$ and $\mathrm{C}$ presented on figure 3 was used as reference to the vertical displacement measurement of point B. The displacement measurement was performed by an LVDT sensor with a gauge length of $5 \mathrm{~mm}$ with an accuracy of $0.1 \%$. The test has been carried out with an imposed displacement (with a rate of $0.2 \mathrm{~mm} \mathrm{~s}^{-1}$ ) of the sleeper until it breaks. 


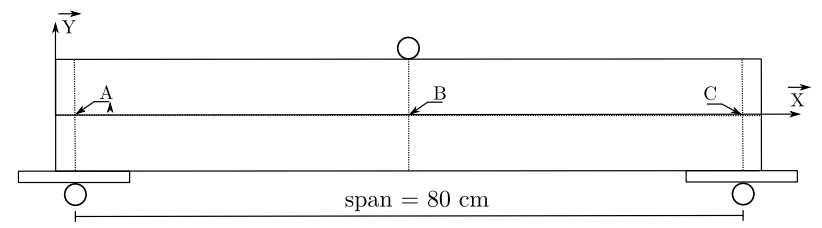

(a) unnotched specimens

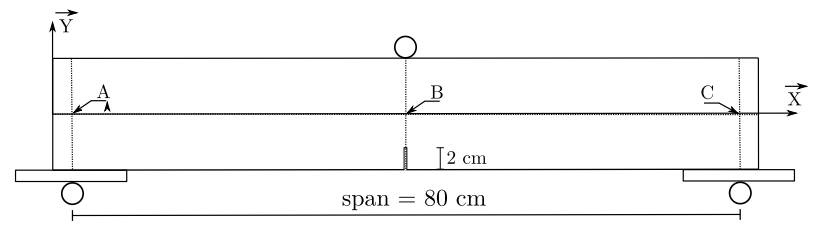

(b) notched specimens

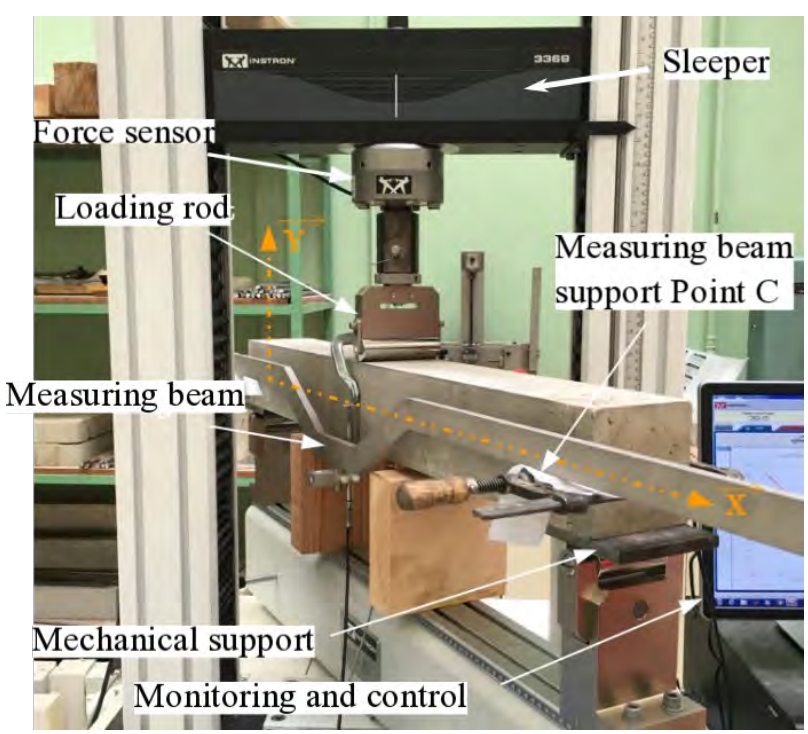

(c) Experimental set up

Figure 3: Bending test devices for notched and unnotched specimens

\subsubsection{Non-destructive mechanical measurement}

For our application, we chose to use ultrasonic measurement that relies on two phenomena, the velocity alteration and the wave attenuation. Ultrasonic tests are both influenced by the size and the material tested. According to these information, the frequency, the transducer and the piezoelectric material have to be chosen in regard of the application. The main idea is the lower the frequency the higher the amount of energy and the deeper the wave penetrates the specimen. However, the higher the frequency, the better the resolution and the sensitivity to small discontinuities and defects. In the present application the goal was to measure the time of flight of the wave on wide specimens (few centimeter). The low frequency (ultrasonic low frequency) allows to increase the amplitude of the back signal and promotes good quality measurement. For ultrasonic measurement, the setup was then composed of a pulser-receiver with a pair of contact transducers of $1.27 \mathrm{~cm}$ diameter, a digital oscilloscope and a computer. The measurements were performed with pulses of compression wave under a frequency of $2.25 \mathrm{MHz}$. Ultrasonic transducers were coupled to concrete by the mean of petroleum jelly.

The distance to be covered by the ultrasonic wave $(\Delta d)$ is then measured using a digital caliper. The travel time of the wave through the material is measured $(\Delta t)$ to obtain the ultrasonic speed of the compression waves. Thus by measuring this velocity, dynamic Young's modulus and Poisson's ratio are calculated by the relationships (5).

$$
\begin{aligned}
& E_{d y n}=\frac{\left(1+\nu_{d y n}\right) \times\left(1-2 \nu_{d y n}\right)}{1-\nu_{d y n}} \times \rho C_{L}^{2} \\
& \nu_{d y n}=\frac{C_{L}^{2}-2 C_{T}^{2}}{2\left(C_{L}^{2}-C_{T}^{2}\right)}
\end{aligned}
$$

with $C_{L}$ and $C_{T}$ respectively the velocity of longitudinal and transverse waves in $\left[\mathrm{m} \mathrm{s}^{-1}\right]$ and $\rho$ the 
density in $\left[\mathrm{kg} \mathrm{m}^{-3}\right]$. However, since the coupling greatly reduces the ultrasonic wave signal, it was not possible to measure the celerity of the $\mathrm{S}$ waves. To be able to determine the dynamic modulus, a Poisson's ratio of 0.23 was assumed.

\subsection{Experimental results}

\subsubsection{Relative mass variation and drying shrinkage}

Figure 4 shows the evolution of imposed relative humidity. In the case of the first drying conditions, the relative humidity is $30 \% \pm 0.4 \%$ and temperature is $25^{\circ} \mathrm{C} \pm 0.01{ }^{\circ} \mathrm{C}$ whereas in the second case it is $45 \% \pm 2.6 \%$ and temperature is $21^{\circ} \mathrm{C} \pm 0.3{ }^{\circ} \mathrm{C}$ respectivly. In the case of $30 \% h_{r}$, the specimens are stored in a climatic chamber, which allows a precise control of the imposed conditions. On the other hand, there were variations on the specimens stored in a controlled room $\left(45 \% h_{r}\right)$ but the values recorded show standard deviations less than $2.7 \%$.

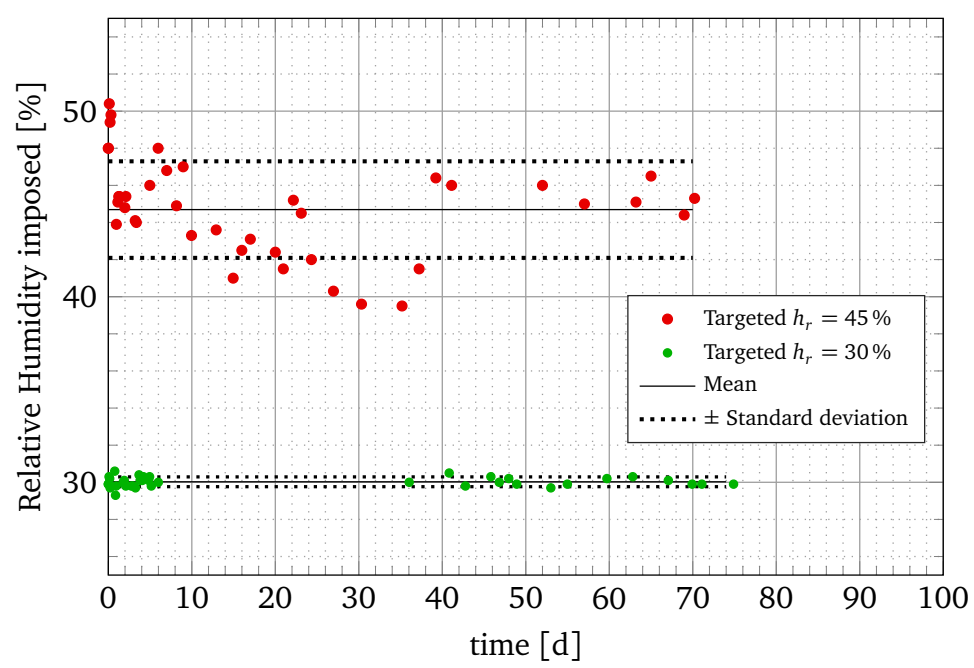

Figure 4: Evolution of environmental conditions for the two campaigns.

Figure 5 gathers results of relative mass variation over 70 days of drying. In green dots are plotted the evolution of samples kept in the first hydric condition and in red for the second one. In both cases (cylindrical or beam samples) there are small variability on the 6 samples monitored. It can be seen that drying conditions have a direct influence on the evolution of mass loss. The drier the conditions are the higher the value of the relative mass variation is. According to figure 5a the relative mass variation after 70 days are respectively $4.2 \%$ and $3.3 \%$. Almost similar values are found for beams (figure $5 \mathrm{~b}$ ) with $4.5 \%$ and $3.3 \%$. The curves presented on the two figures are expressed here as a function of the square root of time (in days $d$ ). It can be seen that the evolution of the relative mass variation is almost linear up to $5 \mathrm{~d}^{0.5}$. Finally, after 70 days of drying, the relative mass variation is not at equilibrium. Thus drying gradients are still existing inside the sample. However, even if each specimen shapes are different resulting in a different internal $\mathrm{RH}$, the equivalent radius of the sample (parameter proportional to the ratio of the volume over the exposed surface) is rather close inducing a transient hydric state also close.

The evolution of drying shrinkage was monitored over a period of 440 days. Figure 6 shows the average results, with its uncertainties of three test pieces expressed as a function of relative mass variation. The final drying shrinkage value obtained was $536 \mathrm{\mu m} \mathrm{m}^{-1}$ for a relative mass variation of $5.16 \%$. The error bars here show the minimum and maximum values. The drying shrinkage kinetics is consistent with the data found in the literature. Several phases can be observed. In particular, an initial dormant phase where drying is observed without high apparent shrinkage [30, 31]. This is followed by an evolution where the drying shrinkage becomes proportional to the relative mass 


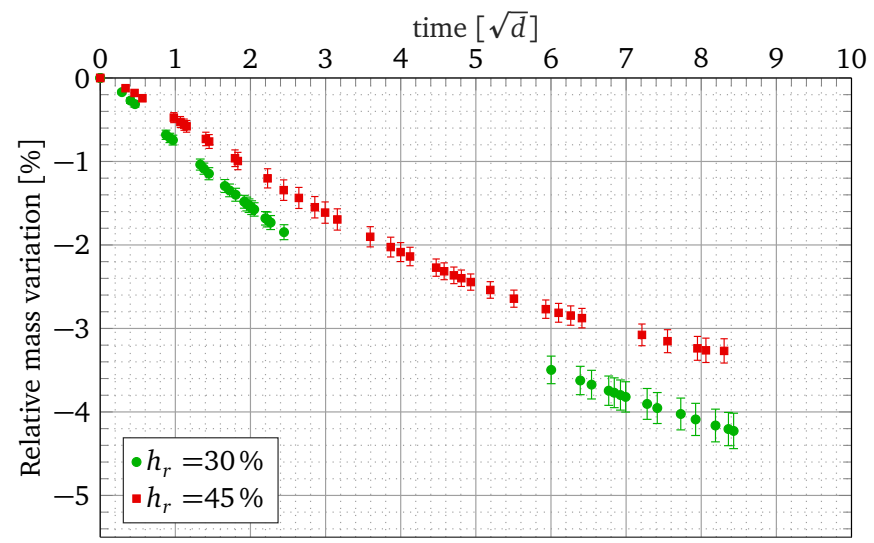

(a) Cylindrical samples $\left(11 \times 22 \mathrm{~cm}^{2}\right)$

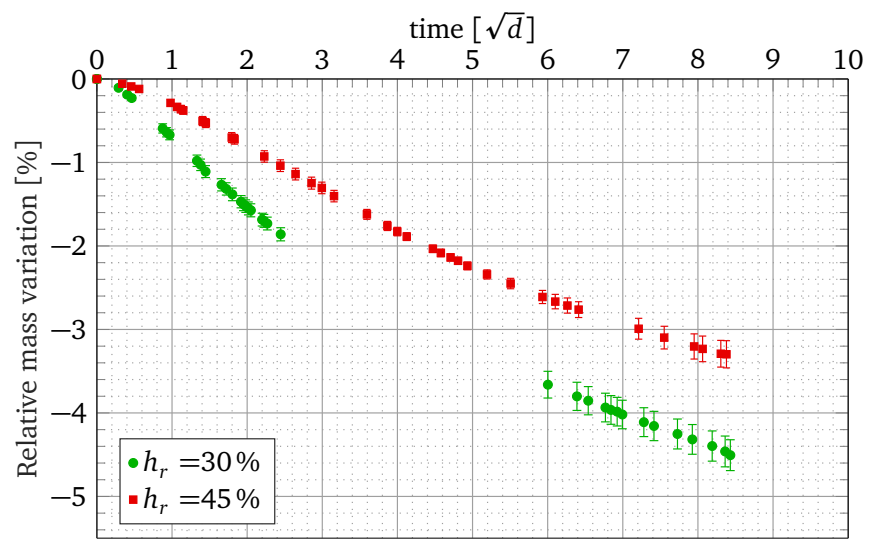

(b) Beam samples $\left(10 \times 10 \times 84 \mathrm{~cm}^{3}\right)$

Figure 5: Evolution of relative mass variation over time. Mean values of 6 samples are presented with one standard deviation error.

variation. And finally, although the water balance is not completely achieved, water content gradients are less important, which implies a slowdown in drying shrinkage, also observed by [30].

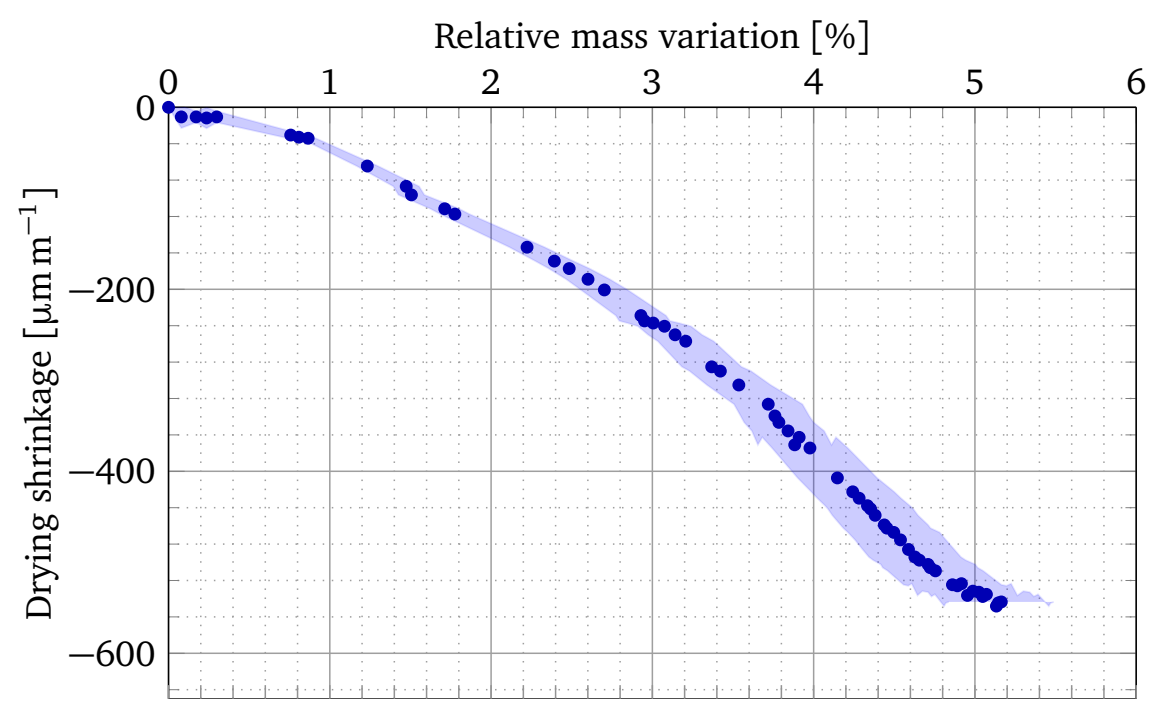

Figure 6: Evolution of drying shrinkage with relative mass variation kept at $45 \% h_{r}$ over 440 days. Measures realized on $7 \times 7 \times 28 \mathrm{~cm}^{3}$ samples.

\subsubsection{Porosity}

Table 2 gathers the porosity obtained for each campaign. The measured porosities range from $14.6 \%$ to $16.2 \%$ with an average of $15.3 \%$ and a reasonable variability. With regard to the water content in the samples, the obtained values ranged from $6.5 \%$ to $7.4 \%$ with an average of $6.9 \%$. The values seemed consistent for this type of material, see for example [32, 33]. Finally, despite the small number of samples, there was a good consistency between the samples of the batches of the first campaign and those of the second one.

Figure 7 presents the evolution of desorption isotherm. The two isotherms obtained have a small variability. The water content at saturation is $7 \%$ and $6.7 \%$ respectively. When focusing on the desorption path from high humidity to low humidity three main phases are observed. A first one, around $h_{r} \in[95,100] \%$, where a strong drop in water content appears, corresponding in the emptying into the large capillary pores. A second one where the water content decreases in a quasi-linear way 


\begin{tabular}{ccccccc}
\hline Campaign & Sample & $\mathrm{m}_{\text {hyd }}[\mathrm{g}]$ & $\mathrm{m}_{\text {sat }}[\mathrm{g}]$ & $\mathrm{m}_{\text {dry }}[\mathrm{g}]$ & $\phi[\%]$ & $w_{\text {sat }}[\%]$ \\
\hline 1 & 1 & 525.1 & 904.5 & 849.2 & 14.6 & 6.5 \\
& 2 & 526.0 & 912.4 & 852.9 & 15.4 & 7.0 \\
& 3 & 523.6 & 909.2 & 848.2 & 15.8 & 7.2 \\
2 & 4 & 513.8 & 895.5 & 833.5 & 16.2 & 7.4 \\
& 1 & 554.1 & 959.0 & 900.5 & 14.6 & 6.6 \\
& 2 & 560.6 & 971.4 & 910.0 & 15.0 & 6.8 \\
\hline
\end{tabular}

Table 2: Mean value of porosity and water mass content (with $\mathrm{m}_{\mathrm{hyd}}$ the hydrostatic mass)

up to $40 \%$ to finally reach a last phase. In both cases this last phase starts around $35 \% h_{r}$ where a jump in water content occurs. In this phase, desorption of inter layer water between inner sheets of C-S-H begins [33] (pore size close to few nanometer according to Kelvin-Laplace equation) and both isotherms are close. This similarity is mainly explained by the structure of C-S-H which is not affected by the material mix parameters [34].

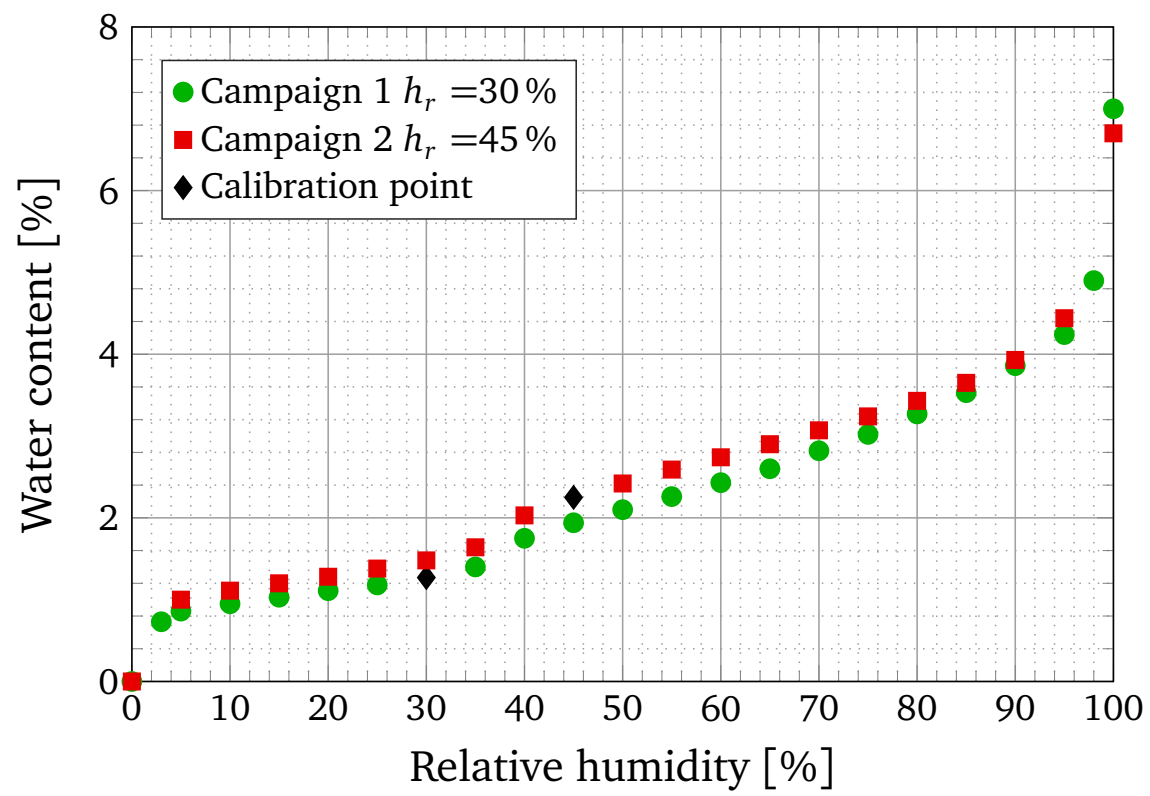

Figure 7: Water vapour desorption isotherm of concrete. Calibration points used in the equation (4) are represented with black diamond plot

\subsubsection{Mechanical properties obtained with destructive methods}

In this section the mechanical properties are highlighted. Compressive followed by unotched bending and finally notched bending results are presented. For all the figures, curves plot the average values of three specimens and error bars stand for the minimum and the maximum of each tests. The colour code chosen to represent the different data is blue for specimens stored in water and red for drying specimens. The macroscopic behaviour of studies at $30 \%$ and $45 \% h_{r}$ are put in parallel in the three cases in order to better understand the impact of drying on mechanical behaviour.

Figure 8 shows the evolution of compression behaviour for the two campaigns where the impact of drying on macroscopic behaviour is clearly observable. In both cases, an increase in the apparent strength of the tested samples is observed with a small variability. All the compressive results are listed in appendix B.1. Concerning the first campaign (figure 8a) the average maximum apparent stress is $33.3 \mathrm{MPa}$ in wet conditions and $35 \mathrm{MPa}$ in dry conditions respectively. For the elastic stiffness, average values of $36 \mathrm{GPa}$ and $33.3 \mathrm{GPa}$ are recorded. Finally for the last campaign (figure $8 \mathrm{~b}$ ) the values recorded are $32.6 \mathrm{MPa}$ in wet conditions and $36.6 \mathrm{MPa}$ in dry ones for the apparent 
compressive strength and $35.9 \mathrm{GPa}$ in wet and $38.2 \mathrm{GPa}$ in dry for the elastic stiffness.

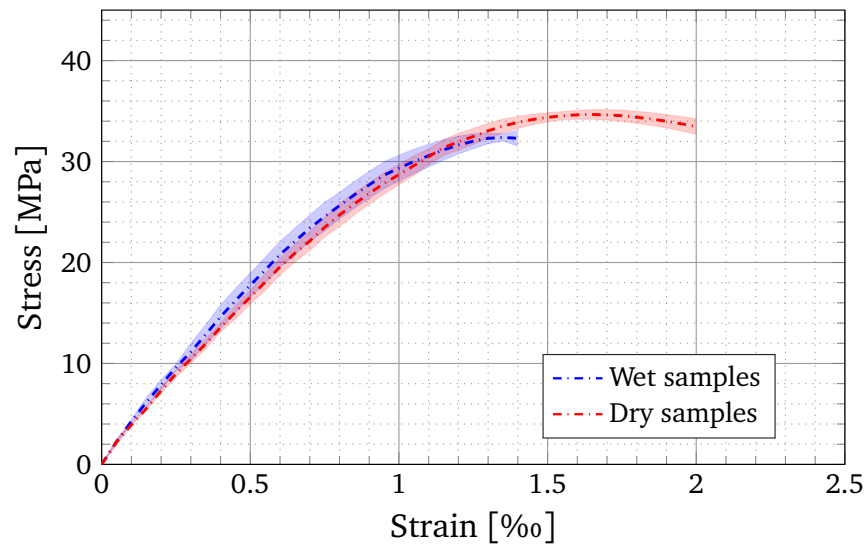

(a) Drying conditions : $h_{r}=30 \%$

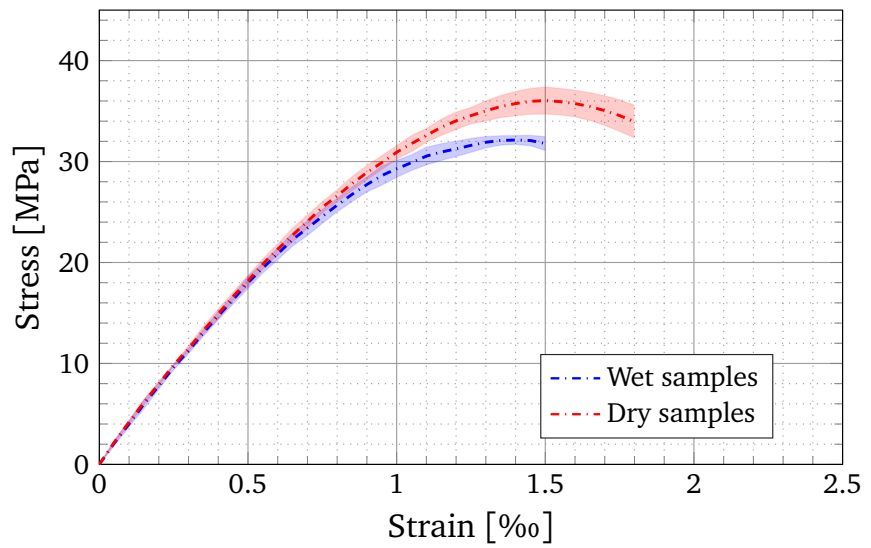

(b) Drying conditions : $h_{r}=45 \%$

Figure 8: Mean Stress-strain curves obtained in compression. Average curves of 3 samples and error bars standing for minimum and maximum value.

The results of the splitting tests performed are presented in appendix B.1. Splitting test data are slightly impacted by drying since the average tensile strength in wet conditions is $3.5 \mathrm{MPa}$ with respect to $3.8 \mathrm{MPa}$ in dry condition for campaign at $30 \%$ of relative humidity and $3.4 \mathrm{MPa}$ compared to $4.1 \mathrm{MPa}$ for the campaign at $45 \% h_{r}$. The values obtained, although few in number, have small variability which ensures a good control of the test protocol. Similarly, the wet values recorded in the case of the two campaigns are relatively close, which suggests that the two materials are rather homogeneous between the two batches.

Figure 9 presents the evolution of the average load versus displacement curves obtained in the two 3-points unnotched bending test campaigns. In both cases, drying slightly modifies the macroscopic response. In these figures, several behaviour phases appear. First, a linear increase that corresponds to the elastic response of the material. This phase ends when the maximum force is reached $\left(F_{\max }\right)$, then a slightly unstable post-peak phase with a drop of load and a large increase in displacement begins. Finally, a last stable softening phase occurs until the beam breaks.

In the framework of notched and unnotched bending tests, three quantities are studied: the maximal stress $\sigma_{\text {peak }}$, the elastic stiffness $\mathbb{K}$ and finally the dissipated energy $W_{\text {diss }}$. For the maximal stress, the value is calculated following the equation (6).

$$
\sigma_{\text {peak }}=\frac{3}{2} \frac{F_{\max } L}{b \times h^{2}}
$$

with $L$ the span, $b$ the width, $h$ the height of the beam near the loading in $[\mathrm{m}], F_{\text {max }}$ the maximal applied load in $[\mathrm{kN}]$. Regarding elastic stiffness, it is obtained by classical relationship (7).

$$
\mathbb{K}=\frac{\alpha \times L^{3}}{48 I}
$$

with $\alpha$ the slope of the curve in the elastic part, $L$ the span $[\mathrm{m}]$ and $I$ the moment of inertia $\left[\mathrm{m}^{4}\right]$ of the beam. Finally, the total dissipated energy is estimated as proposed by Hillerborg [35] by equation (8). Concerning, the energy given due to the weight of the beam and the testing device $\left(w_{s w}\right)$, Guinea et al. [36] proposed the equation (8c) to take into account this non measured energy, with $m$ the mass in $[\mathrm{kg}], g$ the acceleration due to gravity in $\left[\mathrm{m} \mathrm{s}^{-2}\right]$ and $\delta_{0}$ the failure displacement 
in $[\mathrm{m}]$.

$$
\begin{aligned}
W_{\text {diss }} & =\frac{w_{0}+w_{s w}}{S_{\text {frac }}} \\
w_{0} & =\int_{0}^{\delta_{\max }} F(u) d u \\
w_{s w} & =m g \delta_{0}
\end{aligned}
$$

In the case of the first campaign (figure 9a), the average values obtained under wet and drying conditions were 4.6 and $4.5 \mathrm{MPa}$ for the peak strength, 33.1 and $26.1 \mathrm{GPa}$ for the elastic modulus and finally 115 and $162 \mathrm{~J} \mathrm{~m}^{-2}$ for the dissipated energy. The impact of drying on this campaign is mainly observed on the elastic stiffness as well as on the dissipated energy. In the case of the second campaign (figure 9b) only two samples could be taken into account. The maximum strength values were 5.1 and $5.3 \mathrm{MPa}, 33.1$ and $33.3 \mathrm{GPa}$ for the elastic stiffness and finally 122 and $156 \mathrm{~J} \mathrm{~m}^{-2}$ for the dissipated energy. In this campaign it would seem that there is little effect of drying on the behaviour of the material apart from the dissipated energy. For these two figures, all the values obtained are summarised in appendix B.2.

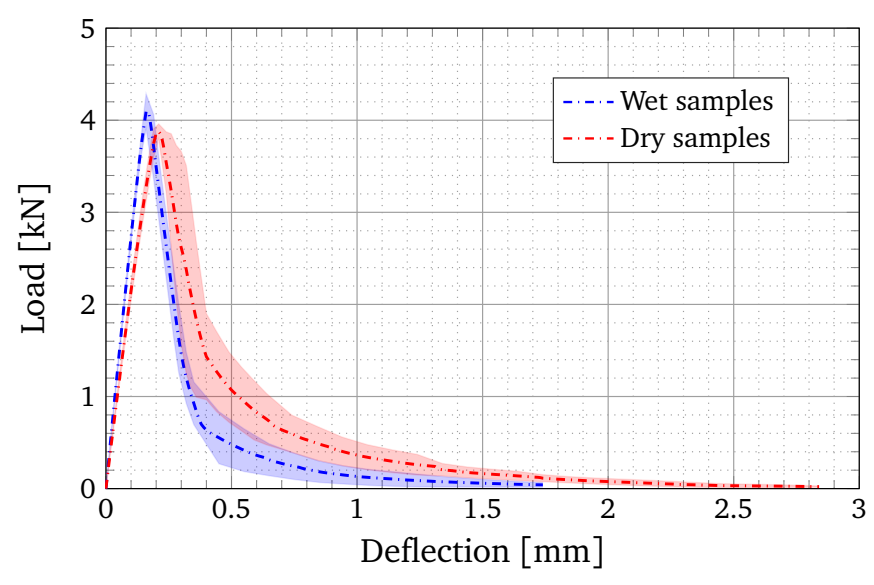

(a) Drying conditions : $h_{r}=30 \%$

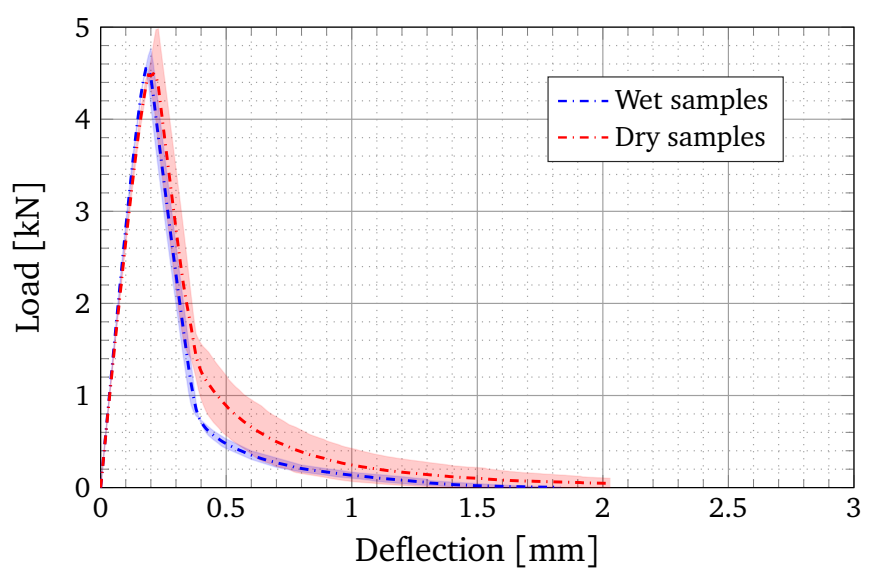

(b) Drying conditions : $h_{r}=45 \%$

Figure 9: Mean Force-Displacement curves obtained by three points bending tests on unnotched beam.

Finally, figure 10 shows the evolution of the 3-points bending tests behaviour in the case of the notched beams. The impact of drying on these two figures is more visible than in the case of unnotched beams. A similar behaviour was found in the case of the unnotched beams with two ready exceptions. The first one is the more pronounced appearance of non-linearities in the pre-peak phase. And the second one concerns the post-peak part which does not show any instability during the softening. As far as the calculation of the different interest parameters is concerned, except for the elastic modulus there are no changes on the post-processing method. For the elastic modulus, a numerical analysis approach was used to obtain an equivalent stiffness of the beam ( $c . f$ appendix A). The average values obtained for these two campaigns are a tensile strength of 3.8 and $4.9 \mathrm{MPa}$, an elastic stiffness of 31.8 and $26.7 \mathrm{GPa}$ and a dissipated energy of 73.9 and $116 \mathrm{~J} \mathrm{~m}^{-2}$ for the first campaign (figure 10a). And for the second (figure 10b) a tensile strength of 3.9 and $4.7 \mathrm{MPa}$, an elastic stiffness of 32.8 and $29.6 \mathrm{GPa}$ and a dissipated energy of 97.9 and $137 \mathrm{~J} \mathrm{~m}^{-2}$.

In both cases, the values of strength and elastic modulus are substantially similar for wet conditions. It is thus again possible to conclude on a good homogeneity of the materials produced between 
the batches. Regarding dissipated energy, the quantities calculated in the wet cases (parameters corresponding to cracking energy) are consistent with those presented in literature (see for instance [37]).

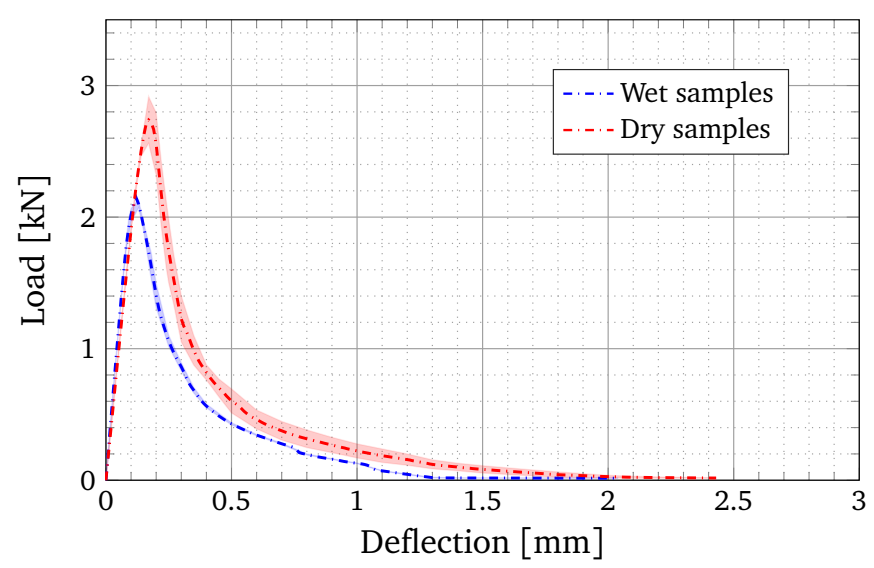

(a) Drying conditions : $h_{r}=30 \%$

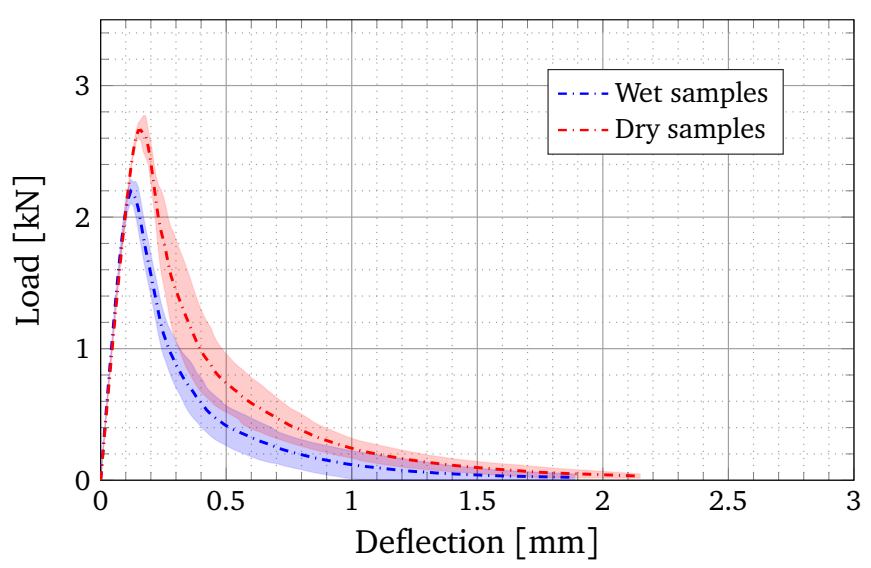

(b) Drying conditions : $h_{r}=45 \%$

Figure 10: Mean Force-Displacement curves obtained by three points bending tests on notched beam.

\subsubsection{Non-destructive measurement of mechanical properties}

The mechanical properties obtained by ultrasonic method are summarized in Tab. 3. The values presented for each specimen are the average of three measurements. For more information, the data set is presented in appendix B. The average wet values are close and do not present much scattering. Celerity values are consistent with those found in the literature, see for instance the work of [38]. The resulting dynamic Young's modulus is in the order of 36 and $37 \mathrm{GPa}$ for both campaigns. Measurements on specimens kept under conditions of $30 \%$ and $45 \%$ relative humidity have dynamic Young's moduli values of 32 and $35 \mathrm{GPa}$ respectively. With or without drying conditions, the values have coefficients of variation very close.

\begin{tabular}{|c|c|c|c|c|c|c|c|c|}
\hline \multirow[t]{3}{*}{ Samples } & \multicolumn{4}{|c|}{$h_{r}=30 \%$} & \multicolumn{4}{|c|}{$h_{r}=45 \%$} \\
\hline & \multicolumn{2}{|c|}{$\mathrm{C}_{L}\left[\mathrm{~m} \mathrm{~s}^{-1}\right]$} & \multicolumn{2}{|c|}{ Dyn modulus [GPa] } & \multicolumn{2}{|c|}{$\mathrm{C}_{L}\left[\mathrm{~m} \mathrm{~s}^{-1}\right]$} & \multicolumn{2}{|c|}{ Dyn modulus [GPa] } \\
\hline & Wet & Dry & Wet & Dry & Wet & Dry & Wet & Dry \\
\hline 1 & 4806 & 4637 & 35.0 & 31.9 & 4863 & 4822 & 36.7 & 35.2 \\
\hline 2 & 4851 & 4660 & 36.4 & 31.6 & 4948 & 4904 & 38.0 & 36.7 \\
\hline 3 & 4942 & 4620 & 37.4 & 29.3 & 4951 & 4752 & 37.7 & 32.5 \\
\hline 4 & 4741 & 4694 & 34.8 & 32.9 & 4807 & 4757 & 35.8 & 33.7 \\
\hline 5 & 4788 & 4735 & 35.2 & 33.3 & 4833 & 4806 & 36.1 & 34.4 \\
\hline 6 & 4733 & 4650 & 35.0 & 32.1 & 4920 & 4836 & 37.4 & 34.9 \\
\hline Mean & 4810 & 4666 & 36.0 & 32.0 & 4887 & 4813 & 37 & 35.0 \\
\hline Standard deviation & 104 & 67 & 1.0 & 2.0 & 118.9 & 81.6 & 1.8 & 1.6 \\
\hline $\mathrm{COV}[\%]$ & 2.1 & 1.4 & 4.1 & 4.8 & 2.4 & 1.7 & 4.8 & 4.7 \\
\hline
\end{tabular}

Table 3: Average values of ultrasonic measurements on bending specimens $10 \times 10 \times 84 \mathrm{~cm}^{3}$ 


\section{Discussions}

\subsection{Drying effects on elastic properties}

In this study, the Poisson's ratio was not investigated. The latter, has only a limited influence in structural modelling. On figure 11 the evolutions of the mean value of apparent elastic stiffness as a function of ambient conditions and relative mass variation are plotted. These evolutions are dependent on the hydric state. The reduction observed in this figure is in agreement with many authors such as [39] or [8, 14]. Several parameters, in competition, can explain this dependence: the capillary pressure which stiffens the material, the shrinkage induced by drying and the strains incompatibilities between the components which reduce the stiffness. Finally as the sample is nonhomogeneous regarding hydric state, a structural effect is also present [40].

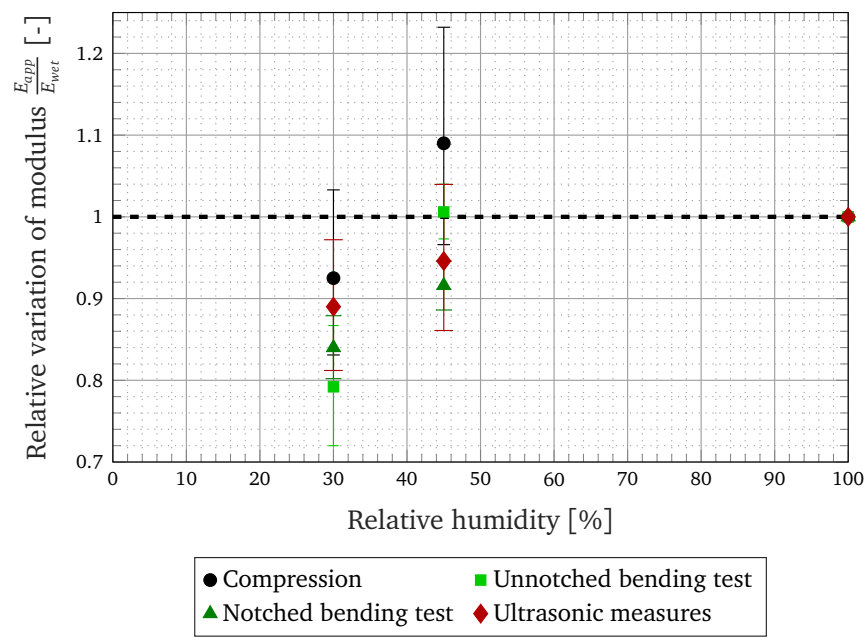

(a) Function of relative humidity condition

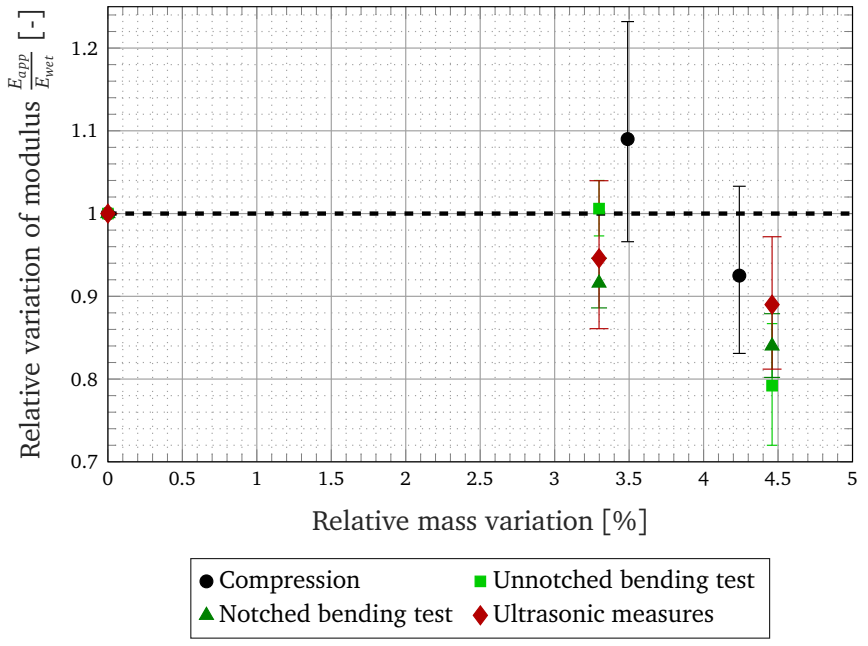

(b) Function of relative mass variation

Figure 11: Evolution of relative variation of elastic properties regarding drying conditions after 70 days

The reduction of the apparent elastic modulus is mainly due to the shrinkage induced cracking. The amplitude of drying shrinkage is reduced by the presence of volumetrically stable limestone aggregates [3]. The difference of behaviour between the aggregate and the paste shrinking will lead to strain incompatibilities and eventually generate microcracks and voids that reduce the apparent elastic modulus. This influence of aggregates is illustrated by Maruyama et al.[14] who find a linear correlation between the decrease in the apparent Young's modulus and the difference in drying shrinkage between a mortar and a concrete. Still according to their work, for the conditions we are interested in, the reduction of the apparent elastic modulus should be in the order of 70 to $80 \%$. Nevertheless, we can think that the hydric gradients in the sample will partially reduce these effects as we can note on the compression and unnotched bending tests in the case of $45 \%$ relative humidity. Finally, it can be noted that the most severe condition leads to the largest decrease. This can probably be explained by both the reduction in hydric gradients (closer to the homogeneous state at the time of the test) but also by the drying rate which can lead to a difference in stress relaxation and more microcracking between the two cases as proposed by Yurtdas et al. [8].

\subsection{Drying effects on strength in compression}

Figure 12 shows the evolution of relative compressive strength as a function of drying and relative mass variation. According to this plot, drying is beneficial in both study cases. This is consistent with the data from $[12,13,20]$. These increases in strength are attributed both to capillary pressure 
which causes suction effects in the pores of the material [20] and to the none homogeneity of the hydric fields in the different specimens [41, 7]. A slight reduction appears between the first and the second case. It can be assumed that in the most severe case, the shrinkage induced cracking develops more microcracking than in the other case. As a result, the load bearing path is modified and the strength is reduced [14].

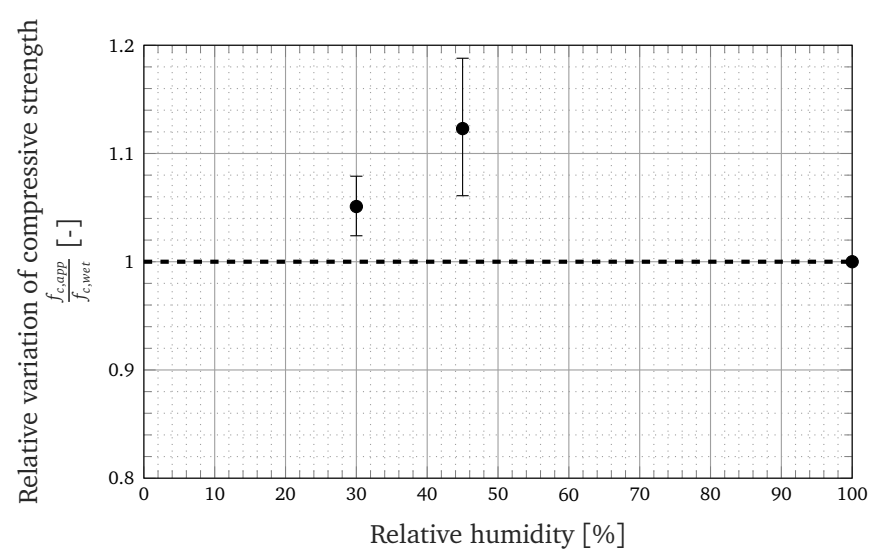

(a) Function of relative humidity condition

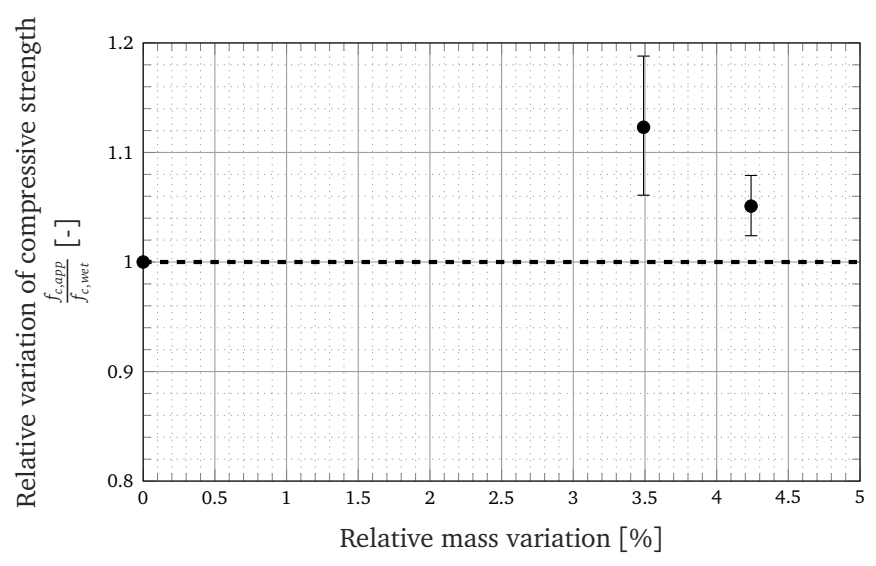

(b) Function of relative mass variation

Figure 12: Evolution of relative variation of compressive strength regarding drying conditions after 70 days

It is well known that hydration has an effect on the compressive strength. It is assumed that saturated samples provide greater hydration than drying samples. Drying samples may have zones where the water content does not allow complete hydration and then consequently should provide a lower strength than saturated sample. Therefore, the increase in relative strength experimentally observed (up to $86 \%$ ) could not be explainable by this difference in hydration.

\subsection{Drying effects on strength in tension, splitting test and bending test}

The evolution of tensile strength as a function of drying obtained by the different standard tests is also related to the competition between the different parameters as presented in section 3.1. In addition to this, [5] showed that in mortar made with Ordinary Portland Cement, there were mainly three phases for the evolution of the tensile strength with the decrease of relative humidity. First an increase in strength due to adhesion of C-S-H between 100 and $60 \%$ of $h_{r}$, then a slight decrease due to the higher number of macropores up to $40 \%$, and finally the densification of C-S-H that increases strength. Regarding all these informations, the tensile strength results presented in figure 13 can be analysed.

As seen on figure 13, tensile strength obtained by splitting tests is positively affected by drying. This observation is in agreement with the work of Hanson [17]. For the least severe hydric case, the strength obtained is the highest. As proposed by Yurtdas [31], it can be assumed that diametric loading of the specimen will promote structural prestressing effects induced by capillary suction, and minimize the impact of micro-cracking induced by drying shrinkage. In addition, the latter is located in a compressed area that has little impact on the test result. This result will be different in the case of direct tensile test as the microcracks will be located in the effective cross-section of the specimen.

In the case of notched and unnotched bending tests, a different impact is noted for the same loading. In one hand, in unnotched bending case, the impact is slight and in the same order of magnitude than the variability. It can be assumed that drying has no real influence here. This result is not in agreement with the findings of [8, 42] which find a decrease in strength on concretes not at equilibrium. This difference may be explained by the size of the specimens used in the different 


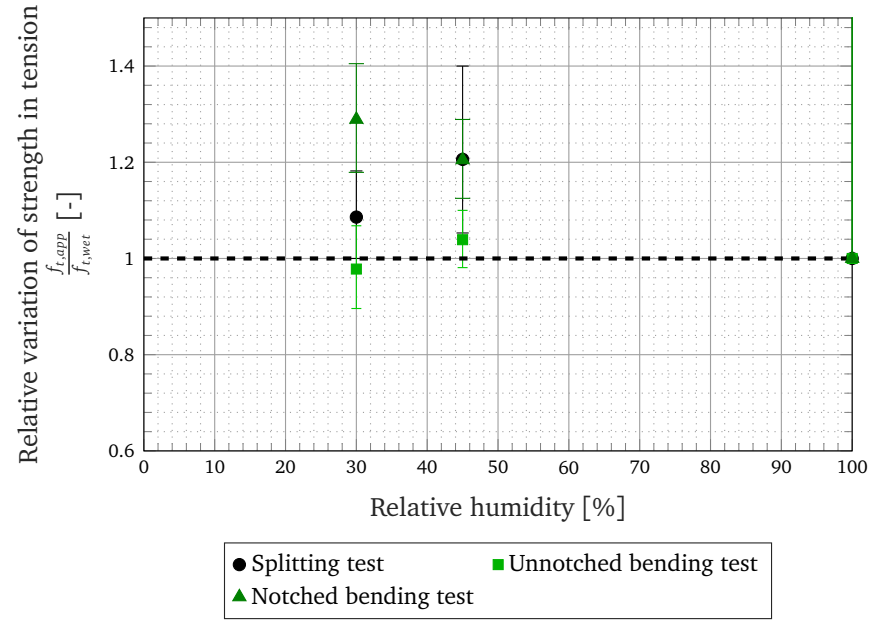

(a) Function of relative humidity condition

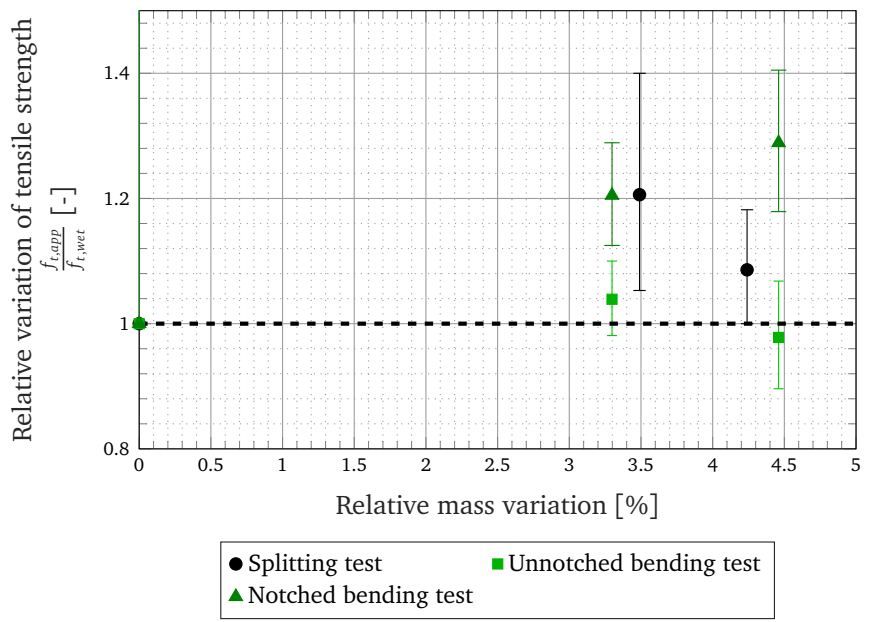

(b) Function of relative mass variation

Figure 13: Evolution of relative variation of tensile strength regarding drying conditions after 70 days

studies (prism $4 \times 4 \times 16 \mathrm{~cm}^{3}$ compared to prisms $10 \times 10 \times 84 \mathrm{~cm}^{3}$ ). In [8, 42] works, the impact of micro-cracking at the cross section is predominant compare to the present case where the location of cracking appears to be the predominant factor.

On the other hand, in the notched bending tests, drying in both cases results in a significant increase in bending strength, as seen in figure 13b. Consequently, the more important the drying is, the more the normalized strength increases. This may appear contradictory to the unnotched case. In notched specimens, the area impacted by drying-induced micro-cracking is sawed, therefore no further effect should be achieved, compared to the unnotched case. Nevertheless, the area subjected to mechanical loading has a lower humidity than the saturated case and no micro-cracking. This may explain the increase observed in the notched bending strength. Cement paste has a higher strength if the relative humidity at the notch is between 100 and $50 \% h_{r}$ [5] which seems a reasonable assumption in our case given the ambiant conditions imposed.

\subsection{Drying effects on fracture energy}

Figure 14 plots the evolution of the fracture energy versus drying. Results include error bars showing one standard deviation for each side. It should be noted that in this case dispersion is important. On both of these figures, fracture energy increase with drying. These results are in agreement with the works of [43, 44]. As for concrete exposed to high temperatures [45], the hydric state inside the porous body changes the amount of energy required to fracture the sample. Indeed, the decrease of saturation degree leads to a higher capillary pressure. This results in an internal state of stress that will make more difficult for the crack to spread [44, 46]. In addition, the micro-cracking state induced by drying and the incompatibilities between aggregates and cement paste, can create a micro-cracking network yielding the cracking path more tortuous. Finally, it should be kept in mind that the cement paste with desaturation seems to be more resistant according to [5].

\section{Conclusions}

The main objective of this study was to characterize the behaviour of ordinary concrete used in french nuclear power plants submitted to drying. For this purpose, two ambient conditions were selected: a severe one $\left(30 \% h_{r}\right)$ and a more standard one $\left(45 \% h_{r}\right)$. The samples were stored for a period of 70 days and then characterized. This characterization focused on the drying behaviour 


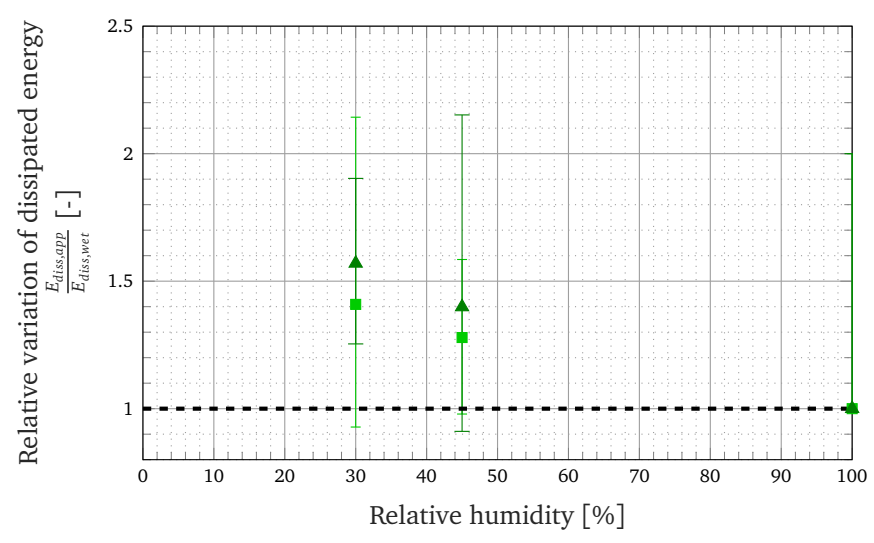

- Unnotched bending test $\Delta$ Notched bending test

(a) Function of relative humidity condition

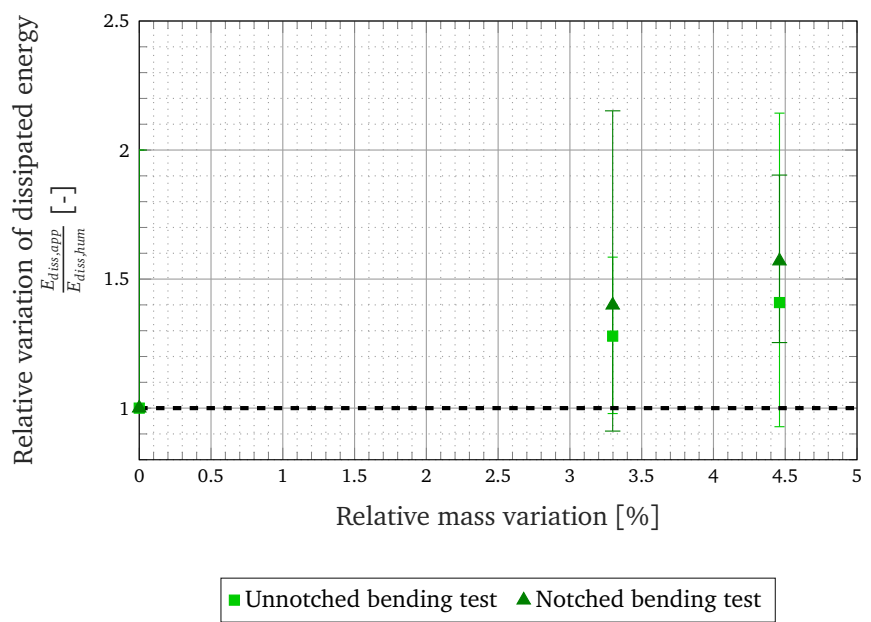

(b) Function of relative mass variation

Figure 14: Evolution of relative values of dissipated energy regarding drying conditions after 70 days

during the conservation phase: evolution of relative mass variation and associated drying shrinkage. Also some data of its microstructure was determined: porosity, water mass content and desorption isotherm. Finally, the residual mechanical behaviour was obtained by means of standard mechanical tests. The following conclusions can be drawn from this study:

- Relative mass variation measurements were undertaken over 70 days under water conditions of $30 \%$ and $45 \%$ respectively. Two different types of geometries were used. The results obtained show small variability. After 70 days of measurement, the relative mass variation still evolves and the samples are not at equilibrium ;

- Drying shrinkage of the material was measured on $7 \times 7 \times 28 \mathrm{~cm}^{3}$ prismatic samples subjected to a $45 \% h_{r}$ environment for 440 days. Three samples were used. After 440 days the relative mass loss is almost at equilibrium and the drying shrinkage is about $536 \mathrm{\mu m} \mathrm{m}^{-1}$;

- The porosity accessible to water was characterized by means of standard method. For both campaigns, the average porosity obtained is $15.3 \%$. The water content was also characterized. An average value of $6.9 \%$ is calculated ;

- The desorption isotherm of the investigated material was characterized by a dynamic sorption method. The operation was carried out for the materials of the two batches. The results obtained show small variability in terms of both kinetics and values ;

- Mechanical properties are impacted by drying. This impact varies according to the tests and is a function of three factors: capillary pressure, induced micro-cracking and strains incompatibilities between the components ;

- The compressive strength of the studied samples is positively affected by drying after 70 days. There is a non-monotonous evolution of the normalized strength as a function of the hydric state of the material, which is not attributed to hydration.

- Young's modulus is in most cases impacted by drying. The more important the drying conditions are, the more micro-cracking develops and then the more the Young's modulus is reduced.

- The tensile strength is affected differently depending on the type of test. For tensile splitting tests, micro-cracking has no effect on the value obtained, while capillary pressure and increased 
strength of the cement paste improve tensile strength. The strength obtained by bending test performed on unnotched beam shows a lower effect after 70 days of drying. Finally, the strength measured on notched bending beams shows a significant influence of drying on the values obtained. This is explained by the potential increase in the strength of the cement paste with drying.

- The dissipated energy by the cracking obtained by the 3-points bending test (notched and unnotched) is strongly impacted by the drying process. A substantial increase in dissipated energy is observed with desaturation.

Finally, all the experimental data collected, together with the creep information given in the appendix, form a complete experimental database that offers the possibility of calibrating hygromechanical models.

\section{Acknowledgement}

The authors would like to thank Stéphane Poyet from CEA for the realization of the DVS tests and for fruitful discussions. 


\section{A Numerical stiffness}

In the case of notched bending test, relationships given by the mechanics of materials, are no longer valid because the inertia along the beam is not constant. It is therefore necessary to calculate the equivalent inertia of the beam to characterize the mechanical properties of the material. To do this, a finite element study has been carried out. If we consider an isotropic elastic model of a beam composed of 8500 cubic elements with 20 nodes, it is possible to vary the geometry of the notch in order to assess the equivalent stiffness of the beam. The classical relationships 9 are used.

$$
\begin{aligned}
\alpha_{\text {num }} & =\frac{F}{u} \\
\alpha_{\text {num }} & =\frac{\beta I E_{\text {num }}}{L^{3}}
\end{aligned}
$$

with $\beta$ a constant conventionally equal to 48 in unnotched bending case, $\mathrm{I}\left[\mathrm{m}^{4}\right]$ the moment of inertia, $E_{\text {num }}[\mathrm{GPa}]$ the Young's modulus and L $[\mathrm{m}]$ the span of the beam. Since the mechanical input parameters are known in the modelling, it is possible to obtain the value of $\gamma$ :

$$
\beta I=\gamma=\alpha_{\text {num }} \frac{L^{3}}{E_{\text {num }}}
$$

Finally, in order to obtain the experimental Young's modulus, relationship 11 is used.

$$
E_{\exp }=\alpha_{\exp } \frac{L^{3}}{\gamma}
$$




\section{B Mechanical data}

\section{B.1 Compressive and splitting tests data}

\begin{tabular}{|c|c|c|c|c|c|c|c|c|}
\hline \multirow[t]{3}{*}{ Samples } & \multicolumn{4}{|c|}{$h_{r}=30 \%$} & \multicolumn{4}{|c|}{$h_{r}=45 \%$} \\
\hline & \multirow{2}{*}{$\begin{array}{l}\sigma_{\max } \\
\text { Wet }\end{array}$} & \multirow{2}{*}{$\frac{[\mathrm{MPa}]}{\text { Dry }}$} & \multicolumn{2}{|c|}{$\mathbb{K}[\mathrm{GPa}]$} & \multirow{2}{*}{$\begin{array}{l}\sigma_{\max } \\
\text { Wet }\end{array}$} & \multirow{2}{*}{$\frac{[\mathrm{MPa}]}{\text { Dry }}$} & \multicolumn{2}{|c|}{$\mathbb{K}[\mathrm{GPa}]$} \\
\hline & & & Wet & Dry & & & Wet & Dry \\
\hline 1 & 32.9 & 35.4 & 33.5 & 33.2 & 31.9 & 36.7 & 35.9 & 37.2 \\
\hline 2 & 33.1 & 34.8 & 38.4 & 34.8 & 32.8 & 35.1 & 33.5 & 40.8 \\
\hline 3 & 33.9 & 34.7 & 36.0 & 31.9 & 33.0 & 37.8 & 35.9 & 36.7 \\
\hline Mean & 33.3 & 35.0 & 36.0 & 33.3 & 32.6 & 36.6 & 35.1 & 38.2 \\
\hline Standard deviation & 0.5 & 0.4 & 2.4 & 1.4 & 0.6 & 1.4 & 1.4 & 2.2 \\
\hline $\mathrm{COV}[\%]$ & 1.6 & 1.1 & 6.8 & 4.3 & 1.7 & 3.7 & 3.9 & 5.9 \\
\hline
\end{tabular}

Table 4: Compression values of maximum stresses and elastic modulus

\begin{tabular}{ccccc}
\hline \multirow{2}{*}{ Samples } & \multicolumn{3}{c}{$h_{r}=30 \%$} & \multicolumn{2}{c}{$h_{r}=45 \%$} \\
\cline { 2 - 5 } & Wet & Dry & Wet & Dry \\
\hline 1 & 3.4 & 3.7 & 3.6 & 4.1 \\
2 & 3.7 & 3.8 & 3.0 & 4.1 \\
3 & 3.5 & 3.9 & 3.8 & 3.9 \\
Mean & 3.5 & 3.8 & 3.4 & 4.1 \\
Standard deviation & 0.2 & 0.1 & 0.4 & 0.1 \\
COV [\%] & 5.7 & 2.7 & 12 & 2.4 \\
\hline
\end{tabular}

Table 5: Maximum tensile stress values obtained by splitting test in $\mathrm{MPa}$

\section{B.2 Unnotched bending test data}

\begin{tabular}{|c|c|c|c|c|c|c|c|c|c|c|c|c|}
\hline \multirow[t]{3}{*}{ Samples } & \multicolumn{6}{|c|}{$h_{r}=30 \%$} & \multicolumn{6}{|c|}{$h_{r}=45 \%$} \\
\hline & \multirow{2}{*}{$\begin{array}{l}\sigma_{\text {peak }} \\
\text { Wet }\end{array}$} & \multirow{2}{*}{$\frac{[\mathrm{MPa}]}{\text { Dry }}$} & \multicolumn{2}{|c|}{$\mathbb{K}[\mathrm{GPa}]$} & \multicolumn{2}{|c|}{$W_{\text {diss }}\left[\mathrm{J} \mathrm{m}^{-2}\right]$} & \multirow{2}{*}{$\begin{array}{l}\frac{\sigma_{\text {peak }}}{\text { Wet }} \\
\text { Wet }\end{array}$} & \multirow{2}{*}{$\frac{[\mathrm{MPa}]}{\text { Dry }}$} & \multicolumn{2}{|c|}{$\mathbb{K}[\mathrm{GPa}]$} & \multicolumn{2}{|c|}{$W_{\text {diss }}\left[\mathrm{J} \mathrm{m}^{-2}\right.$} \\
\hline & & & Wet & Dry & Wet & Dry & & & Wet & Dry & Wet & Dry \\
\hline 1 & 4.7 & 4.5 & 32.2 & 28.0 & 98.1 & 157 & 5.1 & 5.5 & 33.5 & 32.9 & 121 & 181 \\
\hline 2 & 4.4 & 4.6 & 33.5 & 26.1 & 97.2 & 197 & - & 5.2 & 28.1 & 33.7 & - & 132 \\
\hline 3 & 4.8 & 4.3 & 33.6 & 24.4 & 133 & 132 & 5.0 & 1.0 & 32.3 & 18.3 & 123 & 53 \\
\hline Mean & 4.6 & 4.5 & 33.1 & 26.2 & 109 & 162 & 5.1 & 5.3 & 32.9 & 33.3 & 122 & 156 \\
\hline Std dev & 0.2 & 0.2 & 0.8 & 1.8 & 20 & 33 & 0.1 & 0.2 & 0.8 & 0.6 & 1.4 & 35.3 \\
\hline $\mathrm{COV}[\%]$ & 4.5 & 3.4 & 2.4 & 6.9 & 19 & 20 & 1.4 & 4.0 & 2.6 & 1.7 & 1.2 & 23 \\
\hline
\end{tabular}

Table 6: Values of mechanical properties obtained under unnotched bending test after 70 days of drying under different ambiant conditions compare to those kept under water. In this table $\sigma_{\text {peak }}, \mathbb{K}$ and $W_{\text {diss }}$ stand respectively for the stress at the peak load, the elastic stiffness and finally the amount of dissipated energy.

\section{B.3 Notched bending test data}




\begin{tabular}{|c|c|c|c|c|c|c|c|c|c|c|c|c|}
\hline \multirow[t]{3}{*}{ Samples } & \multicolumn{6}{|c|}{$h_{r}=30 \%$} & \multicolumn{6}{|c|}{$h_{r}=45 \%$} \\
\hline & $\sigma_{\text {peak }}$ & [MPa] & $\mathbb{K}$ & $\mathrm{Pa}$ & $W_{d i s}$ & {$\left[\mathrm{~J} \mathrm{~m}^{-2}\right]$} & $\sigma_{\text {peak }}$ & [MPa] & $\mathbb{K}$ & $\mathrm{Pa}]$ & $W_{d i s s}$ & {$\left[\mathrm{~J} \mathrm{~m}^{-2}\right]$} \\
\hline & Wet & Dry & Wet & Dry & Wet & Dry & Wet & Dry & Wet & Dry & Wet & Dry \\
\hline 1 & 3.8 & 5.2 & 31.8 & 27.3 & 72.5 & 136 & 4.0 & 4.4 & 32.4 & 29.0 & 122 & 104 \\
\hline 2 & - & 5.0 & 32.1 & 27.2 & - & 119 & 3.8 & 4.9 & 32.6 & 29.5 & 83.8 & 150 \\
\hline 3 & 3.7 & 4.8 & 31.4 & 25.7 & 75.3 & 93.5 & 4.0 & 4.7 & 31.8 & 30.2 & 88.6 & 157 \\
\hline Mean & 3.8 & 4.9 & 31.8 & 26.7 & 73.9 & 116 & 3.9 & 4.7 & 32.3 & 29.6 & 97.9 & 137 \\
\hline Std dev & 0.1 & 0.3 & 0.4 & 0.9 & 1.9 & 21 & 0.1 & 0.2 & 0.4 & 0.6 & 20.9 & 28.7 \\
\hline $\mathrm{COV}[\%]$ & 1.1 & 5.4 & 1.1 & 3.4 & 2.6 & 18 & 2.3 & 4.5 & 1.6 & 1.8 & 21 & 21 \\
\hline
\end{tabular}

Table 7: Values of mechanical properties obtained under notched bending test after 70 days of drying under different ambiant conditions compare to those kept under water. In this table $\sigma_{\text {peak }}, \mathbb{K}$ and $W_{\text {diss }}$ stand respectively for the stress at the peak load, the elastic stiffness and finally the amount of dissipated energy.

\section{B.4 Ultrasonic measurement}

\begin{tabular}{|c|c|c|c|c|c|c|c|c|}
\hline \multirow[t]{3}{*}{ Samples } & \multicolumn{4}{|c|}{$h_{r}=30 \%$} & \multicolumn{4}{|c|}{$h_{r}=45 \%$} \\
\hline & \multicolumn{2}{|c|}{$\mathrm{C}_{L}\left[\mathrm{~m} \mathrm{~s}^{-1}\right]$} & \multicolumn{2}{|c|}{ Dyn modulus [GPa] } & \multicolumn{2}{|c|}{$\mathrm{C}_{L}\left[\mathrm{~m} \mathrm{~s}^{-1}\right]$} & \multicolumn{2}{|c|}{ Dyn modulus [GPa] } \\
\hline & Wet & Dry & Wet & Dry & Wet & Dry & Wet & Dry \\
\hline \multirow[t]{3}{*}{1} & 4784 & 4626 & 34.7 & 31.8 & 4837 & 4757 & 36.3 & 34.3 \\
\hline & 4878 & 4644 & 36.0 & 32.0 & 4849 & 4897 & 36.5 & 36.3 \\
\hline & 4755 & 4640 & 34.2 & 32.0 & 4903 & 4812 & 37.3 & 35.1 \\
\hline \multirow[t]{3}{*}{2} & 4841 & 4690 & 36.3 & 32.0 & 4943 & 4853 & 37.9 & 36.0 \\
\hline & 4841 & 4690 & 36.3 & 32.0 & 4995 & 4996 & 38.7 & 38.1 \\
\hline & 4871 & 4600 & 36.7 & 30.7 & 4905 & 4864 & 37.3 & 36.1 \\
\hline \multirow[t]{3}{*}{3} & 4854 & 4635 & 36.1 & 29.5 & 4850 & 4688 & 36.1 & 31.6 \\
\hline & 5062 & 4594 & 39.2 & 29.0 & 4895 & 4892 & 36.8 & 34.4 \\
\hline & 4911 & 4631 & 36.9 & 29.5 & 5109 & 4676 & 40.1 & 31.5 \\
\hline \multirow[t]{3}{*}{4} & 4759 & 4626 & 35.0 & 32.0 & 4544 & 4821 & 32.0 & 34.6 \\
\hline & 4776 & 4778 & 35.3 & 34.1 & 4850 & 4698 & 36.4 & 32.8 \\
\hline & 4687 & 4679 & 34.0 & 32.7 & 5026 & 4752 & 39.1 & 33.6 \\
\hline \multirow[t]{3}{*}{5} & 4716 & 4704 & 35.1 & 32.9 & 4845 & 4811 & 36.3 & 34.5 \\
\hline & 4958 & 4701 & 35.8 & 32.8 & 4889 & 4846 & 37.0 & 35.0 \\
\hline & 4690 & 4801 & 34.7 & 34.2 & 4766 & 4762 & 35.1 & 33.8 \\
\hline \multirow[t]{3}{*}{6} & 4804 & 4776 & 36.1 & 33.9 & 5006 & 4855 & 38.7 & 35.1 \\
\hline & 4657 & 4567 & 33.9 & 31.0 & 4851 & 4858 & 36.4 & 35.2 \\
\hline & 4737 & 4607 & 35.1 & 31.5 & 4904 & 4794 & 37.2 & 34.3 \\
\hline Mean & 4810 & 4666 & 36.0 & 32.0 & 4887 & 4813 & 37 & 35.0 \\
\hline Standard deviation & 104 & 67 & 1.0 & 2.0 & 118.9 & 81.6 & 1.8 & 1.6 \\
\hline $\mathrm{COV}[\%]$ & 2.1 & 1.4 & 4.1 & 4.8 & 2.4 & 1.7 & 4.8 & 4.7 \\
\hline
\end{tabular}

Table 8: Ultrasonic measurements on bending specimens $10 \times 10 \times 84 \mathrm{~cm}^{3}$ 


\section{VeRCoRs additional data}

In the framework of VeRCoRs project [25], a monitoring of delayed strains is carried out over a period of 10 months. Tests are done by EDF CEIDRE on cylindrical samples with dimensions of $16 \times 100 \mathrm{~cm}^{2}$. All samples are stored in the same conditions: a temperature of $20^{\circ} \mathrm{C}$ and a relative humidity of $50 \%$. Creep tests have been performed under a compressive load of $12 \mathrm{MPa}$ applied by a hydraulic press after 90 days. Strains are monitored by the mean of strain gauges. Longitudinal and radial strains are recorded.

As the specimens of VeRCoRs and those in this study are not of similar size, it is necessary to make the results non-dimensional to be able to compare the data. Since drying shrinkage is associated with drying, which is a diffusive phenomenon, it is possible to plot the evolution of shrinkage as a function of the square root of time divided by the equivalent radius of the specimen [47]. A shape coefficient is required to switch from one geometry to another. These shapes coefficients are determined numerically.

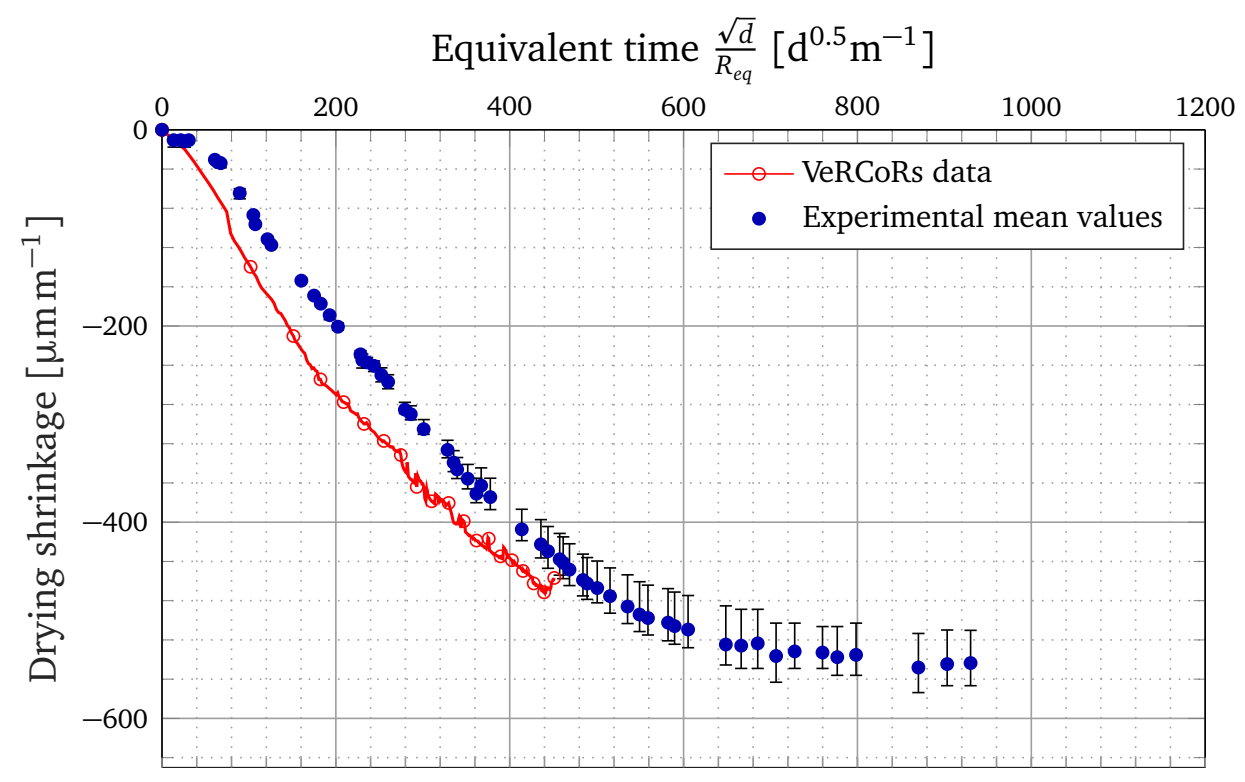

Figure 15: Evolution of drying shrinkage compare to VeRCoRs drying shrinkage. Equivalent radius $\left(R_{e q}\right)$ equals respectively to $3.8 \mathrm{~cm}$ for VeRCoRs data and $1.6 \mathrm{~cm}$ for the experimental data. For informations, the shapes coefficients used are respectively 0.95 and 1.03 . 
Figure 16 plots the evolution of delayed strains measured over the entire period.

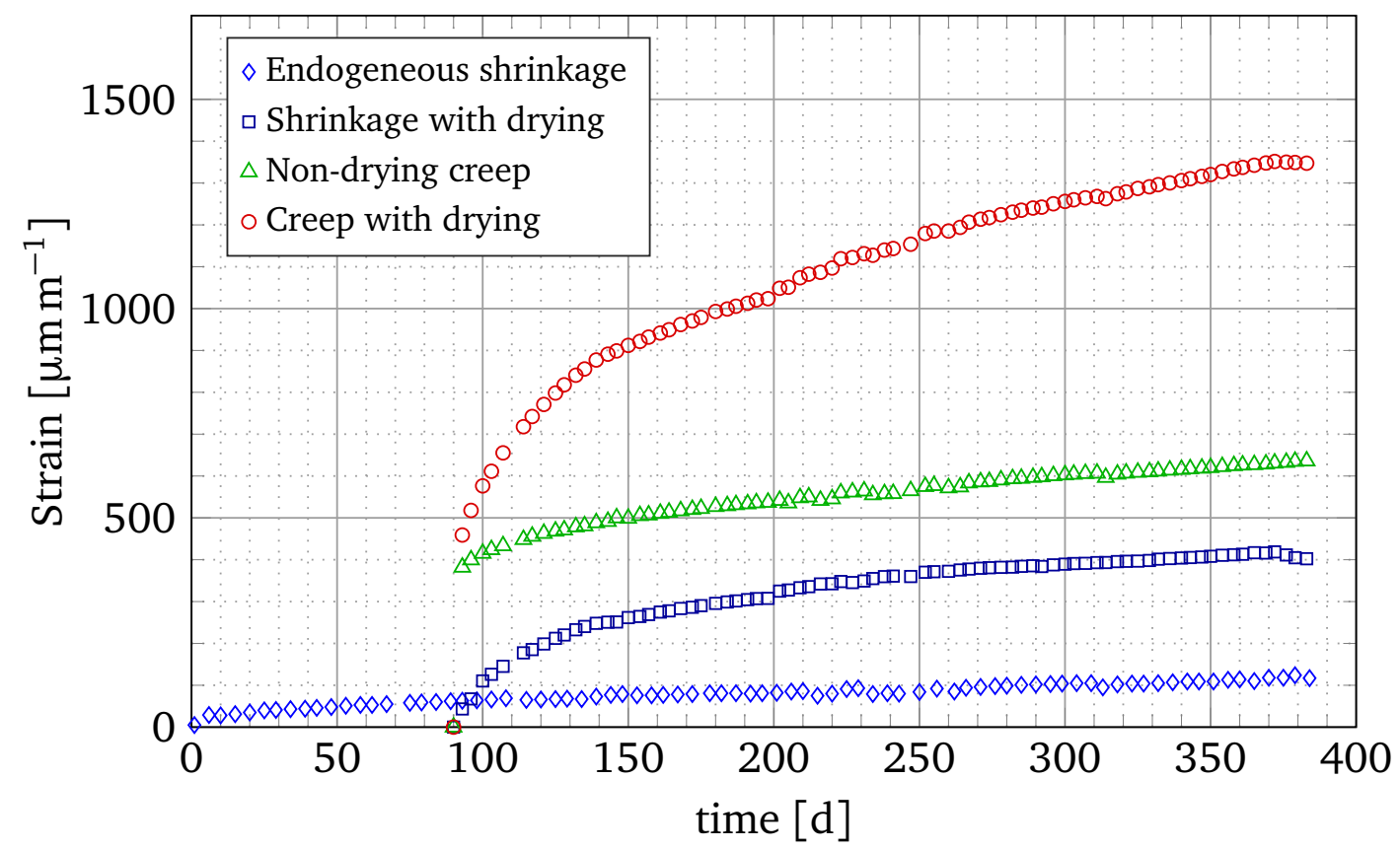

Figure 16: Delayed strains from VeRCoRs data 


\section{References}

[1] A.-M. A. Hamami A.A., Turcry P., Influence of mix proportions on microstructure and gas permeability of cement pastes and mortars, Cement and Concrete Research 42 (2) (2012) 490498. doi:https://doi.org/10.1016/j.cemconres.2011.11.019.

URL https://www.sciencedirect.com/science/article/abs/pii/S0008884611003048\#!

[2] S. H. Kosmatka, B. Kerkhoff, W. C. Panarese, Design and control of concrete mixtures, Vol. 15 ${ }^{\text {th }}$, Portland Cement Assoc., Skokie, IL, 2002.

[3] J. Bisschop, J. Van Mier, Effect of aggregates on drying shrinkage microcracking in cement-based composites, Materials and Structures 35 (8) (2002) 453-461. doi:10.1007/BF02483132.

[4] A. Idiart, J. Bisschop, A. Caballero, P. Lura, A numerical and experimental study of aggregateinduced shrinkage cracking in cementitious composites, Cement and Concrete Research 42 (2) (2012) 272 - 281. doi:https://doi.org/10.1016/j.cemconres.2011.09.013. URL http://www.sciencedirect.com/science/article/pii/S0008884611002602

[5] I. Maruyama, Y. Nishioka, G. Igarashi, K. Matsui, Microstructural and bulk property changes in hardened cement paste during the first drying process, Cement and Concrete Research 58 (2014) 20 - 34. doi:https://doi.org/10.1016/j.cemconres.2014.01.007.

URL http://www.sciencedirect.com/science/article/pii/S0008884614000088

[6] C. Di Bella, M. Wyrzykowski, P. Lura, Evaluation of the ultimate drying shrinkage of cementbased mortars with poroelastic models, Materials and Structures 50 (1) (2016) 52. doi:10. $1617 /$ s $11527-016-0870-0$.

URL https://doi.org/10.1617/s11527-016-0870-0

[7] F. M. Bartlett, J. G. MacGregor, Effect of moisture condition on concrete core strengths, Materials Journal 91 (3) (1994) 227-236.

[8] I. Yurtdas, N. Burlion, J.-F. Shao, A. Li, Evolution of the mechanical behaviour of a high performance self-compacting concrete under drying, Cement and Concrete Composites 33 (3) (2011) 380 - 388. doi:https://doi.org/10.1016/j.cemconcomp.2010.12.002. URL http://www.sciencedirect.com/science/article/pii/S0958946510001940

[9] A. Abbas, M. Carcasses, J. P. Ollivier, Gas permeability of concrete in relation to its degree of saturation, Materials and Structures 32 (1) (1999) 3-8. doi:10.1007/BF02480405.

URL https://doi.org/10.1007/BF02480405

[10] N. Burlion, I. Yurtdas, F. Skoczylas, Comportement mécanique et séchage de matériaux à matrice cimentaire: Comparaison mortier/béton, Revue française de génie civil 7 (2) (2003) 145-165. doi:10.1080/12795119.2003.9692486.

[11] R. Mills, Strength-maturity relationship for concrete which is allowed to dry, in: RILEM International Symposium on Concrete and Reinforced Concrete in Hot Countries (Haifa), In: Neville, A.M. (Ed.), Properties of Concrete, fourth ed., Pearson Prentic Hall, 1995, 1960, pp. 601-602.

[12] F. Wittmann, Surface tension skrinkage and strength of hardened cement paste, Matériaux et Construction 1 (6) (1968) 547-552. doi:10.1007/BF02473643.

URL http://dx.doi.org/10.1007/BF02473643

[13] N. Burlion, F. Bourgeois, J.-F. Shao, Effects of desiccation on mechanical behaviour of concrete, Cement and Concrete Composites 27 (3) (2005) 367-379. doi:10.1016/j.cemconcomp. 2004. 05.004 . 
[14] I. Maruyama, H. Sasano, Y. Nishioka, G. Igarashi, Strength and young's modulus change in concrete due to long-term drying and heating up to $90^{\circ} \mathrm{C}$, Cement and Concrete Research 66 (2014) 48 -63. doi:https://doi.org/10.1016/j.cemconres.2014.07.016.

URL http://www.sciencedirect.com/science/article/pii/s0008884614001562

[15] F. Wittmann, Deformation of concrete at variable moisture content, in: Mechanics of Geomaterials, In: Mechanics of Materials, Ed. Z. Bazant, (John Wiley and Sons Ltd), 1985, pp. 425-459.

[16] J.-M. Torrenti, Comportement multiaxial du béton: aspects expérimentaux et modélisation, Ph.D. thesis, Ecole Nationale des Ponts et Chaussées (1987).

[17] J. Hanson, Effects of Curing and Drying Enviroments on Splitting Tensile Strength of Concrete, in: Journal Proceedings of American Concrete Institute, Vol. 65, 1968, pp. 535-543.

[18] S. Pihlajavaara, A review of some of the main results of a research on the ageing phenomena of concrete: Effect of moisture conditions on strength, shrinkage and creep of mature concrete, Cement and Concrete Research 4 (5) (1974) 761-771. doi:10.1016/0008-8846(74)90048-9.

[19] J. Brooks, A. Neville, A comparison of creep, elasticity and strength of concrete in tension and in compression, Magazine of Concrete Research 29 (100) (1977) 131-141. arXiv:http: //dx.doi.org/10.1680/macr.1977.29.100.131, doi:10.1680/macr.1977.29.100.131. URL http://dx.doi.org/10.1680/macr.1977.29.100.131

[20] I. Yurtdas, H. Peng, N. Burlion, F. Skoczylas, Influences of water by cement ratio on mechanical properties of mortars submitted to drying, Cement and Concrete Research 36 (7) (2006) 12861293. doi:10.1016/j.cemconres.2005.12.015.

[21] H. Sasano, I. Maruyama, A. Nakamura, Y. Yamamoto, M. Teshigawara, Impact of drying on structural performance of reinforced concrete shear walls, Journal of Advanced Concrete Technology 16 (5) (2018) 210-232. doi:10.3151/jact.16.210.

[22] A. Michou, A. Hilaire, F. Benboudjema, G. Nahas, P. Wyniecki, Y. Berthaud, Reinforcementconcrete bond behavior : experimentation in drying conditions and meso-scale modeling, Engineering Structures 101 (15) (2015) 570-582. doi:https://doi.org/10.1016/j.engstruct. 2015.07 .028$.

[23] F. Benboudjema, F. Meftah, J. Torrenti, Interaction between drying, shrinkage, creep and cracking phenomena in concrete, Engineering Structures 27 (2) (2005) 239-250. doi:10.1016/j. engstruct.2004.09.012.

URL http://www.sciencedirect.com/science/article/pii/S0141029604003359

[24] F. Soleilhet, F. Benboudjema, X. Jourdain, F. Gatuingt, Role of pore pressure on cracking and mechanical performance of concrete subjected to drying, Cement and Concrete Composites 114. doi:https://doi.org/10.1016/j.cemconcomp.2020.103727.

[25] E. Galenne, B. Masson, A new mock-up for evaluation of the mechanical and leak-tightness behaviour of npp containment building, in: International Conference on numerical modeling strategies for sustainable concrete structures., SSCS, Aix-en-Provence, France, 2012.

[26] NF-P18-459, Essai pour béton durci : essai de porosité et de masse volumique, Tech. rep., Afnor (2010). 
[27] S. Poyet, K. Trentin, E. Amblard, The use of sorption balance for the characterization of the water retention curve of cement-based materials, Journal of Advanced Concrete Technology 14 (2016) 354-367. doi:10.3151/jact.14.354.

[28] NF-EN-12390-2, Essai pour béton durci : résistance à la compression des éprouvettes, Tech. rep., Afnor (Avril 2012).

[29] NF-EN-12390-6, Essai pour béton durci : détermination de la résistance en traction par fendage d'éprouvettes, Tech. rep., Afnor (Avril 2012).

[30] L. Granger, J.-M. Torrenti, P. Acker, Thoughts about drying shrinkage: Experimental results and quantification of structural drying creep, Materials and Structures 30 (10) (1997) 588-598. doi:https://doi.org/10.1007/BF02486900.

URL https://link. springer.com/article/10.1007/BF02486900

[31] I. Yurtdas, Couplage comportement mécanique et dessiccation des matériaux à matrice cimentaire: étude expérimentale sur mortiers, Ph.D. thesis, Lille 1 (2003).

[32] G. Villain, A. Ihamouten, X. Dérobert, Determination of concrete water content by coupling electromagnetic methods: Coaxial/cylindrical transition line with capacitive probes, NDT and E International 88 (Supplement C) (2017) 59 - 70. doi:https://doi.org/10.1016/j.ndteint. 2017.02 .004$.

URL http://www.sciencedirect.com/science/article/pii/S096386951730107X

[33] Z. Wu, H. Wong, N. Buenfeld, Transport properties of concrete after drying-wetting regimes to elucidate the effects of moisture content, hysteresis and microcracking, Cement and Concrete Research 98 (Supplement C) (2017) 136 - 154. doi:https://doi.org/10.1016/j.cemconres . 2017.04 .006$.

URL http://www.sciencedirect.com/science/article/pii/S0008884616311322

[34] V. Baroghel-Bouny, M. Mainguy, T. Lassabatere, O. Coussy, Characterization and identification of equilibrium and transfer moisture properties for ordinary and high-performance cementitious materials, Cement and Concrete Research 29 (8) (1999) 1225-1238. doi:10.1016/ S0008-8846(99)00102-7.

[35] A. Hillerborg, The theoretical basis of a method to determine the fracture energy GF of concrete, Materials and Structures 18 (4) (1985) 291-296. doi:10.1007/BF02472919.

[36] G. Guinea, J. Planas, M. Elices, Measurement of the fracture energy using three-point bend tests: Part 1-Influence of experimental procedures, Materials and Structures 25 (4) (1992) 212-218. doi:10.1007/BF02473065.

[37] F. H. Wittmann, K. Rokugo, E. Brühwiler, H. Mihashi, P. Simonin, Fracture energy and strain softening of concrete as determined by means of compact tension specimens, Materials and Structures 21 (1) (1988) 21-32. doi:10.1007/BF02472525.

URL https://doi.org/10.1007/BF02472525

[38] S. Popovics, Effects of uneven moisture distribution on the strength of and wave velocity in concrete, Ultrasonics 43 (6) (2005) 429-434. doi : https://doi.org/10.1016/j.ultras. 2004. 09.007.

URL http://www.sciencedirect.com/science/article/pii/S0041624X04002689

[39] T. Okajima, T. Ishikawa, K. Ichise, Moisture effect on the mechanical properties of cement mortar, Transactions of the Japan Concrete Institute 2 (1980) 125-132. 
[40] P. Acker, C. Boulay, P. Rossi, On the importance of initial stresses in concrete and of the resulting mechanical effects, Cement and Concrete Research 17 (5) (1987) 755-764. doi:10. 1016/0008-8846(87) 90038-X.

[41] S. Popovics, Effect of curing method and final moisture condition on compressive strength of concrete, in: Journal Proceedings, Vol. 83, 1986, pp. 650-657.

[42] S. Walker, D. L. Bloem, Effects of curing and moisture distribution on measured strength of concrete, in: Highway Research Board Proceedings, Vol. 36, 1957, pp. 334-346.

[43] Z. P. Bazant, P. C. Prat, Effect of temperature and humidity on fracture energy of concrete, ACI Materials Journal 85 (4) (1988) 262-271.

[44] H. Kallel, H. Carré, C. La Borderie, B. Masson, N. Tran, Effect of temperature and moisture on the instantaneous behaviour of concrete, Cement and Concrete Composites 80 (2017) 326 332. doi:https://doi.org/10.1016/j. cemconcomp.2017.03.021.

URL http://www.sciencedirect.com/science/article/pii/S0958946517302986

[45] A. Menou, G. Mounajed, H. Boussa, A. Pineaud, H. Carre, Residual fracture energy of cement paste, mortar and concrete subject to high temperature, Theoretical and Applied Fracture Mechanics 45 (1) (2006) 64-71. doi:https://doi.org/10.1016/j.tafmec.2005.11.007. URL http://www.sciencedirect.com/science/article/pii/S0167844205000984

[46] F. Benboudjema, Modélisation des déformations différees du béton sous sollicitations biaxiales. Application aux enceintes de confinements de bâtiments réacteurs des centrales nucléaires., Ph.D. thesis, Université de Marne la Vallée (2002).

[47] E. e. L. A. Samouh, Hamza et Rozière, Interprétation des mesures du retrait de dessiccation des bétons autoplaçants (bap), Rencontres AUGC-IBPSA, Chambery, France, 2012. doi:10. $13140 / 2.1 .1348 .3044$. 